\title{
Compressive behaviour of fired-clay brick and lime mortar masonry components in dry and wet conditions
}

\author{
D. V. Bompa $(\mathbb{D} \cdot$ A. Y. Elghazouli $(\mathbb{C}$
}

Received: 11 December 2019/Accepted: 12 May 2020/Published online: 26 May 2020

(C) The Author(s) 2020

\begin{abstract}
This paper examines the fundamental mechanical properties of masonry elements incorporating fired-clay bricks and hydraulic lime mortars under ambient-dry and wet conditions, corresponding to $48 \mathrm{~h}$ submersion in water. In addition to complementary material characterisation assessments, two types of specimens are tested: cylindrical cores in compression, and wall elements in compression. Overall, a detailed account of more than 50 tests is given. Apart from conventional measurements, the use of digital image correlation techniques enables a detailed assessment of the influence of moisture on the constitutive response, confinement effects and mechanical properties of masonry components. The uniaxial compressive strengths of wet brick elements and brick-mortar components, resulting from tests on cylindrical cores with height-to-depth ratios of around two, are shown to be 13-18\% lower than those in ambient-dry conditions. The tests also show that enhanced confinement levels in brick units mobilise $67-92 \%$ higher strengths than in the corresponding
\end{abstract}

D. V. Bompa $(\bowtie) \cdot$ A. Y. Elghazouli

Department of Civil and Environmental Engineering, Imperial College London, London, UK e-mail: d.bompa@surrey.ac.uk

A. Y. Elghazouli

e-mail: a.elghazouli@imperial.ac.uk

D. V. Bompa

Department of Civil and Environmental Engineering, University of Surrey, Guildford, UK unconfined cylinders. Moreover, experimental observations indicate that the presence of significant confinement reduces the influence of moisture on the mechanical properties as a function of the brick and mortar joint thickness and their relative stiffness. As a result, the failure of wet masonry walls in compression is found to be only marginally lower than those in ambient-dry conditions. Based on the test results, the influence of moisture on the constitutive response and mechanical properties of masonry components is discussed, and considerations for practical application are highlighted.

Keywords Masonry $\cdot$ Moisture $\cdot$ Brick-mortar interface $\cdot$ Compressive strength

\section{Introduction}

Clay bricks and stone blocks have been widely used as the main construction materials in historic structures. These are rarely provided with protection systems against moisture or rising damp, nor against significant temperature variations. Amongst the main causes of degradation of heritage masonry is the presence of high moisture content resulting from the capillary absorption of groundwater. It is recognised that moisture can affect both the mechanical characteristics of masonry, as well as the plaster and rendering, 
and its effects need to be identified in combination with other structural problems [1-3]. A fundamental understanding and quantification of moisture effects on the mechanical properties of porous building materials such as masonry is hence required [4].

Compressive tests on brick units submersed in water were shown in previous studies to have a lower strength in comparison to their dry counterparts [5]. It was also shown that the compressive strength decreases proportionally with the moisture content [6]. Average elastic modulus-to-compressive strength ratios obtained from tests on prismatic samples were found to be $14 \%$ lower for specimens with high moisture in comparison to those in dry conditions [7]. It was also noted that the compressive strength reduction due to moisture was a result of strength losses in both the mortar (10-26\% depending on the mortar type) and the brick unit (10\%). Other tests on compression elements showed a significant drop in capacity in the range of $60 \%$ for a moisture content of $15.81 \%$ by weight compared to their counterparts for a $3.5 \%$ moisture content by weight [8].

Clay-bearing rock strengths depend strongly on the weathering processes such as heating and cooling, wetting and drying, and freezing and thawing cycles [9-11]. A direct effect of moisture on such materials is the reduction in toughness due to particle swelling $[12,13]$. Saturated clay-bearing rocks were reported to have a compressive strength and elastic modulus up to about $90 \%$ of oven-dried counterparts [14]. An analysis of thirty-five dry and saturated sandstones indicated that although these have different mineral contents, grain size, porosity, among others, they have similar general characteristics under wet conditions [15]. A reduction in tangent and secant moduli in the range of $25 \%$ was observed for all saturated cases in comparison to dry samples.

Other studies have indicated that the interface mortar-brick shear response is dependent on the moisture content, porosity, mortar strength and conditioning type [16, 17], with saturation leading to deterioration in strength and stiffness [18]. The mechanical properties of masonry elements depend strongly on the internal pore structure of the brick as well as the type of the mortar. The response of bricks in wet conditions depends on their pore distribution and production technology [19]. As historic buildings were most commonly made of handmade low-fired clay bricks [5], this type of manufacturing process resulted in highly porous bricks in which water can infiltrate easily [20]. It is widely accepted that, heritage fired-clay bricks are generally characterised by variable open porosity of up to $45-50 \%$ [21].

In addition to the characteristics of the bricks, the mortar type is a key factor in controlling the height of rising damp and the amount of subsequent evaporation [22]. For example, high porosity mortars such as those typically found in historic structures can have moisture content up to $20 \mathrm{wt} . \%$, whilst in a low porosity mortar (e.g. cement mortar) this is up to $3 \mathrm{wt} . \%$ [23]. Quasi-static tests on dry, wet and submerged conditions indicated that the compressive strength of brick masonry increases with an increase in the compressive strength of the mortar and decreases with an increase in the degree of saturation [24].

Common binders and binder components in historic structures are lime, hydraulic lime, cement, pozzolans and clay [25-27]. Lime mortars can incorporate nonhydraulic or hydraulic limes [28]. Hydraulic lime mortars set and harden by reaction with water, whilst non-hydraulic lime mortars harden by reaction with carbon dioxide [29]. Natural hydraulic limes can have various contents of calcium silicate or levels of hydraulicity which define the class of the material [29, 30]. Typically, mortars incorporating hydrated lime or hydraulic lime have a light porous structure which may permit some capillary flow and, hence, facilitate the development of degradation mechanisms due to moisture transfer [31, 32].

As noted above, some studies have examined the mechanical properties of masonry elements under dry and wet conditions [e.g. 5, 8, 14, 19, 20]. The mechanical performance of masonry incorporating fired-clay bricks and mortars with relatively low elastic moduli have however been limited (e.g. limecement mortars [16] or lime-only mortars [18, 33-35], with most available studies focusing on masonry incorporating cement mortars [7, 8, 23, 32]. The latter are not appropriate for the conservation of heritage masonry, as such repointing mortar produces problems such as brick spalling [36-38].

In this paper, the performance of fired-clay bricklime mortar components in ambient-dry and wet conditions, corresponding to $48 \mathrm{~h}$ submersion in water, are investigated through a series of compressive tests on cylindrical cores and wall elements. The bricks and mortars were selected to resemble the properties of masonry components investigated in a 
wider research programme on the management and conservation of heritage masonry structures in Historic Cairo [39]. Initial site assessment indicated various levels of moisture from ambient-dry to fully saturated, as well as signs of environmental deterioration mechanisms, due to seasonal variations and high groundwater levels. The research programme aims at offering detailed safety evaluation of historical structures using non-linear computational models with due account for the influence of moisture on the structural performance of masonry structures. Hence, this paper provides a complementary study focusing on the assessment and quantification of the influence of moisture on the constitutive response and mechanical properties of masonry components.

\section{Experimental methodology}

\subsection{Characteristics of bricks and mortar}

\subsubsection{Mortar properties}

Mortars incorporating natural hydraulic lime (NHL) with a binder-to-aggregate ratio of $1: 3$ by volume were selected for the study, as these are typically used for conservation works on historic masonry [40]. An eminently hydraulic binder (NHL5), with a specific gravity of 2.70 and a specific weight of $26.5 \mathrm{kN} / \mathrm{m}^{3}$, conforming to BS EN 459-2, was used in the lime mortars [41, 42]. The hydraulic binder contains silicates, calcium aluminates, and calcium hydroxide, obtained by firing crushed marl limestone in kilns [42]. After removal from kilns it was subjected to slaking (hydration), which involves the addition of controlled amounts of water, and then ground to powder [29].

These are singular binders which combine hydraulic with air setting, obtained by carbonation with atmospheric $\mathrm{CO}_{2}$ [43]. The free lime $\mathrm{Ca}(\mathrm{OH})_{2}$ is above $15 \%$ for NHL5, whilst the sulphates content is below $2 \%$. In addition to tap water, 'soft sand' typically used for bricklaying and pointing applications, manufactured to BS EN 13,139 [44], was added to all mortar mixes. This type of sand has rounded particles and is essential for enhanced mix workability in comparison to sharp sand [45]. The sieve analysis shown in Fig. 1, indicates that the particle size of the sand was below $1.0 \mathrm{~mm}$. The specific gravity and bulk specific weight of the sand were 2.65 and around 15.7

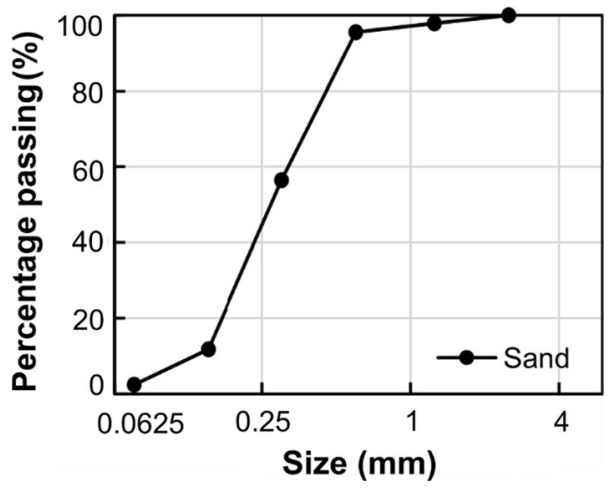

Fig. 1 Sieve analysis of the sand used in mortars

$\mathrm{kN} / \mathrm{m}^{3}$, respectively, whilst its water absorption was around $5 \%$.

The mixing procedure from BS EN 1015-2 [46] and BS EN 459-2 [41] was followed to produce mortars from dry constituents and water [47]. The consistency of fresh mortar was assessed by means of a flow table according to BS EN 1015-3 [48]. The water was adjusted in order to obtain workable mortars with a flow in the range of $190 \mathrm{~mm}$. The mortars were prepared in 20-L batches using a rotary mixer with a 40-L capacity. The dry constituents were mixed together for a period of $180 \mathrm{~s}$, followed by the gradual addition of water, and were then further mixed for another $180 \mathrm{~s}$. Besides the mortar used for bricklaying, another set of cubic $(50 \times 50 \times 50 \mathrm{~mm})$ samples and prismatic $(25 \times 25 \times 150 \mathrm{~mm})$ samples were used for strength assessments. After casting, the mortar samples were covered with a plastic sheet and removed from moulds after 5 days. These were then kept near the masonry specimens in laboratory conditions.

Compressive and flexural strengths were determined from compression and four-point tests according to BS EN 1015-11 [49]. These material tests were carried out at $41 \pm 1$ days from preparation, at the start of the experimental testing of all specimens. In addition to the mechanical properties in wet and ambient-dry conditions, the moisture content of both conditioning cases for NHL mortar samples was assessed. The ambient-dry samples and those submersed in tap water for a minimum of $48 \mathrm{~h}$, were dried in an oven for $6 \mathrm{~h}$ at $60{ }^{\circ} \mathrm{C}$ and another for $18 \mathrm{~h}$ at $105{ }^{\circ} \mathrm{C}$ until the sample mass was relatively constant. The moisture content of the lime mortars was $2.54 \%$ 
by weight (wt.\%) for ambient-dry samples and 10.80 (wt.\%) for those submersed in water.

\subsubsection{Brick units}

Commercial fired-clay facing solid bricks were used for the construction of the walls and the extracted cores [50]. The nominal compressive strength assessed according to BS EN 771-1 [51] for elements tested perpendicular to bed face was $13 \mathrm{MPa}$, whilst the water absorption $w_{\mathrm{a}}<10 \%$. To assess the mechanical properties of the materials from the brick units, compressive tests perpendicular or parallel to bed face as well as on cylindrical cores, were carried out as described in the following sections. As in the case of the lime mortar samples, the moisture content of bricks was assessed using the same conditioning procedure. The moisture content of ambient-dry bricks was $0.07 \%$ by weight (wt. \%), and $10.46 \mathrm{wt} . \%$ for those submersed in water. The moisture content values for submersed samples show that the water absorption of the lime mortars and lime bricks were very similar.

From readily available materials, this type of firedclay bricks has the closest physical and mechanical properties to those from the Mausoleum of Fatima Khatun (Umm al-Salih) built in the thirteenth century in Cairo, which is assessed in the project [39]. Site surveys indicated that: (i) 'red' bricks (used for the foundation) have a compressive strength $\left(f_{\mathrm{b}}\right)$ of about 5.2 $\mathrm{MPa}$ and water absorption $w_{\mathrm{a}}=27.5 \%$, (ii) 'light brown' bricks have an $f_{\mathrm{b}}=14.7 \mathrm{MPa}$ and $w_{\mathrm{a}-}$ $=18.13 \%$ and (iii) 'dark brown' bricks have an $f_{\mathrm{b}}=22.7 \mathrm{MPa}$ and $w_{\mathrm{a}}=13.4 \%$ [39]. The characteristics of available fired-clay bricks, chosen in this investigation, are hence in the low range of those from the site survey, and typically found in heritage masonry [52, 53], yet they can be used for comparative assessments and structural repair studies.

The measured brick sizes based on an average of 30 samples were $229 \times 111 \times 66 \mathrm{~mm}( \pm 2.0 \times 2.9 \times$ $0.8 \mathrm{~mm}$ ). This variation in size is due to the slop moulding manufacturing procedure, which involves introducing a wet clay mixture into a mould without a bottom or top end, and which is then manually smoothened. The specific weight of the bricks is 17.1 $\mathrm{kN} / \mathrm{m}^{3}$. The freeze/thaw resistance category of the fired-clay bricks from this study, as specified by the manufacturer, is F2 and corresponds to severe exposure conditions. The classification for the active water soluble salts content category is S0, indicating no requirements for salts content. The latter is related to the soluble salts naturally occurring in clays used for brick manufacturing.

\subsection{Specimen details}

This section presents the specimen configuration, conditioning and testing methods employed to assess the compressive strength of fired-clay brick units, brick cylinders and masonry elements (brick-mortar cores and small walls) under ambient-dry and wet conditions. The latter correspond to $48 \mathrm{~h}$ submersion of samples in water. Only ambient-dry and wet specimens have been considered for this study, as results from the literature $[6,8,18]$ indicate that there is minimal or no influence of moisture on the mechanical properties of the materials, when the moisture content is below $3 \%$ by weight. Close inspection of the data obtained from submersing masonry specimens and independent masonry components (bricks, mortar samples and bricks with mortar joints) in water for a period of $24 \mathrm{~h}$, indicates that after $3 \mathrm{~h}$, the masonry specimens have a relatively constant weight. It is hence considered that for the geometries investigated in this paper, submersion of $48 \mathrm{~h}$ is sufficient to ensure fully saturated conditions at given ambient temperature and water pressure.

The test specimens prepared (Fig. 2) were divided equally into two groups: wet and dry. Half of the specimens were kept in laboratory conditions ( $\left.\mathrm{T}=24-30{ }^{\circ} \mathrm{C}, \mathrm{RH}=30-50 \%\right)$, whilst the remaining specimens were in wet conditions. It is worth noting that the small samples (mortar, brick units, cylindrical brick and brick-mortar cores) were fully submersed in water, whilst the small walls were submersed over $3 / 5$ of their depth for the above period to closely represent the site conditions considered. As the water level was maintained constant to compensate for the loss due to capillary absorption, the walls reached similar moisture content throughout their depth, as described below.

\subsubsection{Brick units and cylindrical cores}

To assess the actual material properties of brick units (described in Sect. 2.1.2), compressive tests were carried out on (i) $10 \times$ brick units perpendicular to the bed face (Fig. 3a), (ii) $10 \times$ brick units parallel to the 


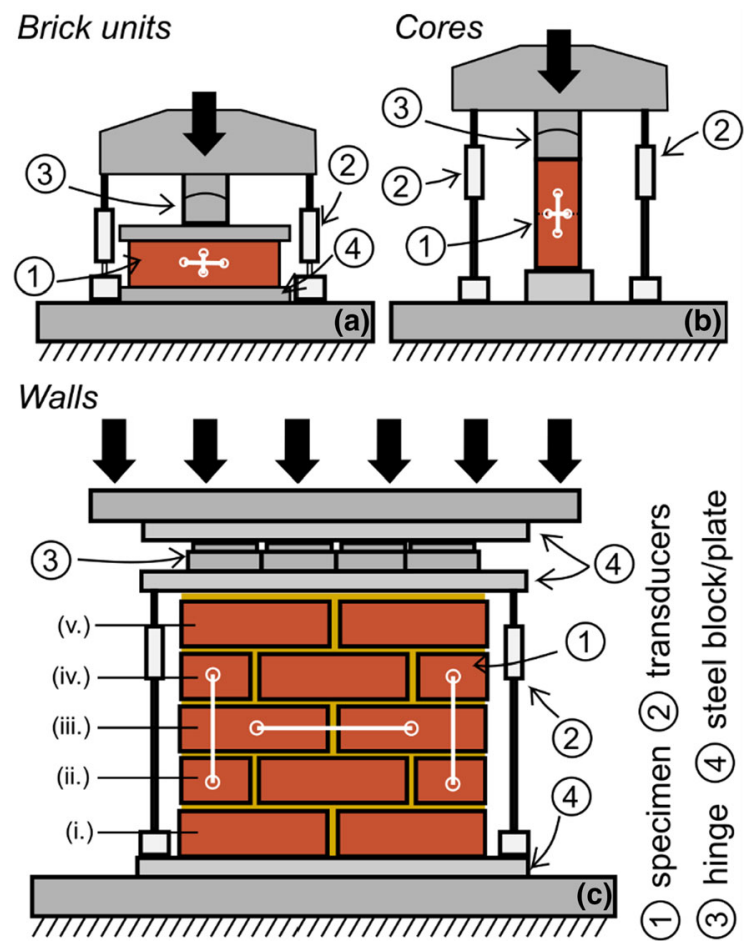

Fig. 2 Testing arrangements: a brick units, b cylinders, $\mathbf{c}$ walls (note that brick unit and cylinder specimens were tested in different configurations and aspect ratios)

bed face (Fig. 3b), (iii) $10 \times$ cylindrical cores with an aspect ratio (height-to-diameter $h / d$ ) around 1.0 (Fig. 3c) and (iv) $10 \times$ two-stacked cylindrical cores with an aspect ratio around 2.0 (Fig. 3d).

In addition to the brick-only samples described above, masonry specimens incorporating: (i) two cores with a mortar joint of about $15 \mathrm{~mm}$ in between ( $h / d>2.0$ ) (Fig. 3e), and (ii) two cores stacked with mortar layers at the top, bottom and between the brick cores $(h / d>2.0)$ (Fig. 3f), were extracted from the wall elements described in Sect. 2.2.2. These brickmortar configurations were chosen to assess the influence of the mortar joint on the compressive strength of masonry elements, as well as to determine the material-dependent fracture initiation and propagation.

Brick units tested parallel to the bed face are labelled PRy, whilst those tested perpendicular to the bed face are labelled PPy (in which ' $y$ ' indicates the specimen conditioning: D for ambient-dry, $\mathrm{W}$ for wet). The cylindrical specimen references adopt the format $\mathrm{Cxyz}$, in which $\mathrm{x}$ indicates the type of specimen ( 0 for single brick core samples, A for two stacked- brick-brick-samples, B for brick-mortar-brick samples and $\mathrm{C}$ for mortar-brick-mortar-brick-mortar samples), y indicates the specimen conditioning (D for ambient-dry, $\mathrm{W}$ for wet), and $z$ the specimen sequence (a, b, c, etc.).

Considering the brick geometry mentioned before $(229 \times 111 \times 66 \mathrm{~mm})$, the brick units tested parallel to the bed face (PRy) had an aspect ratio $h / d=0.29$, whilst those tested perpendicular to the bed face (PPy) had an aspect ratio of $h / d=0.48$. Single brick core samples COyz had a diameter of $69.4 \pm 0.1 \mathrm{~mm}$ and an average $h / d=0.95$. Brick-brick specimens $C A y z$ made of two cored samples had a diameter of $69.4 \pm 0.1 \mathrm{~mm}$ and an average $h / d=1.98$. Specimens $C B y z$ had a diameter of $69.4 \pm 0.1 \mathrm{~mm}$ at the brick elements and an average $h / d=2.20$ due to the presence of a mortar layer, which was about $13.6 \pm 1.7 \mathrm{~mm}$ thick and had a diameter of $68.4 \pm 0.91 \mathrm{~mm}$. The diameter of the last group CCyz was $69.1 \pm 1.0 \mathrm{~mm}$ at the brick components, had an average $h / d=2.58$, and incorporated mortar layers with an average thickness of $13.1 \pm 2.5 \mathrm{~mm}$ and an average diameter of $68.5 \pm 0.7 \mathrm{~mm}$.

Tests on brick units in two orientations and cylinders with different slenderness, as described above, enable a better comparison of the fundamental mechanical properties and those obtained from standardised tests. It should be noted however that due to the triaxial confinement effects produced by the loading plates, as shown in Fig. $3 \mathrm{~h}$, leading to an enhancement in strength and ductility, brick unit tests perpendicular or parallel to the bed face would not reliably capture the uniaxial strength properties of the material. When steel plates are used to load specimens, triaxially-confined zones develop in the parts of the specimen below the plates [54]. This primarily occurs due to shear stresses between the loading platen and the specimen due to the incompatibility in lateral expansion and stiffness between the two [55]. As shown in Fig. 3b, the zones of triaxial confinement include most of the specimen length at small $h / d$ ratios, whilst relatively large areas without restraint and uniaxial stress states develop as the specimen height increases. Hence, a higher strength is measured at low $h / d$, since the triaxial compressive strength is typically larger than the uniaxial compressive strength $[54,56]$. Considering the above, the confinement effects are minimised or eliminated when $h / d \geq 2.0$, and a uniaxial stress state exists at mid-height of the 


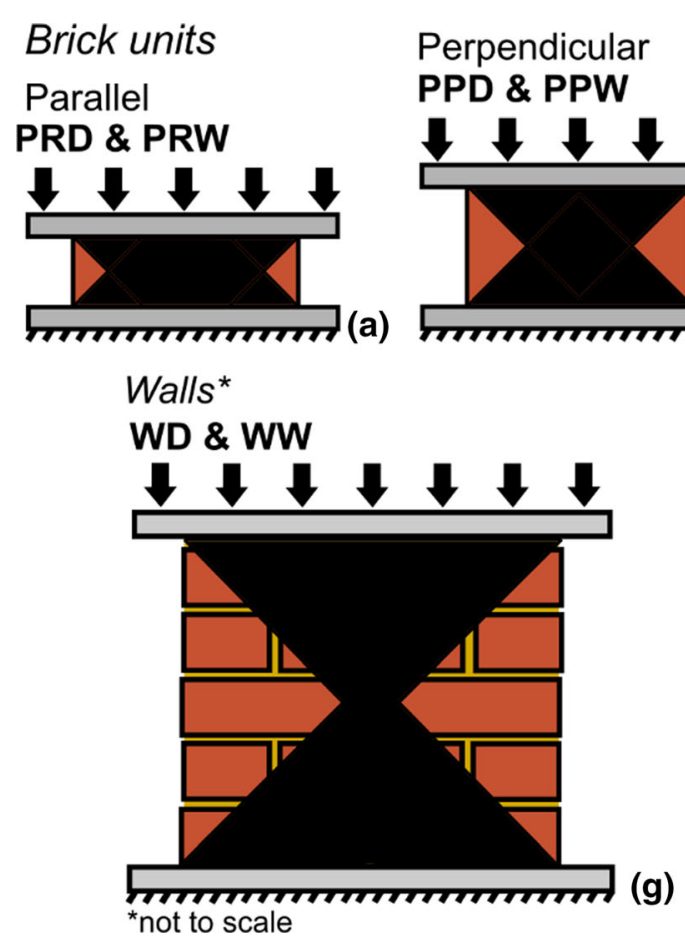

Fig. 3 Configurations of brick units and cylindrical specimens: a brick units parallel to bed joint, $\mathbf{b}$ brick units perpendicular to the bed joint, c brick-only single core, $\mathbf{d}$ brick-only two-stacked cores, e masonry brick-mortar-brick cylindrical core, $\mathbf{f}$ masonry

specimen. As for brick units tested perpendicular or parallel to bed face, specimens with $h / d=1.0$ would develop higher strengths due to confinement effects produced by loading plates above and below the specimen.

In order to assess the flexural properties of the bricks, additional three-point bending tests on notched units were carried out. Prismatic samples with square cross-sections were obtained by cutting the brick elements in two using a diamond saw. The sample length was the same as a brick unit $(\approx 229 \mathrm{~mm})$, whilst its depth and width were both $51 \pm 1.5 \mathrm{~mm}$. A notch of $5 \mathrm{~mm}$ depth was then created using a grinder provided with a diamond disc. The faces that were in contact with the support/loading plates or bearings were ground in order to achieve planeness and parallelism as indicated in BS EN 771-1 [51].

\subsubsection{Wall specimens}

Tests on wall specimens of $b \times h \times t=472 \times 403$ $\times 110 \mathrm{~mm}( \pm 2.5 \times 5.1 \times 0.8 \mathrm{~mm})$ were carried

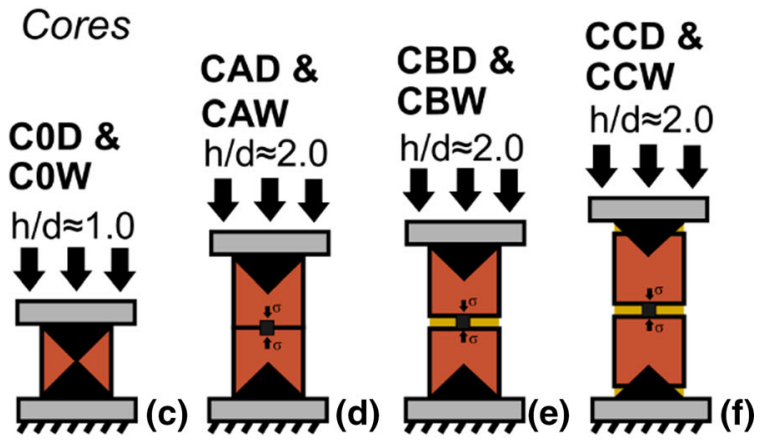

(1) load from rigid platens

(2) triaxial confinement

(3) uniaxial stress state $\mathbf{i}_{\sigma}^{\circ}$

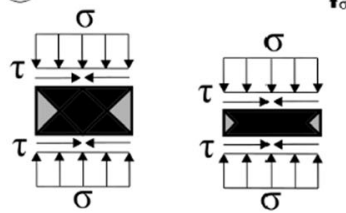

(h)

cylinder with three mortar joints and two brick; $\mathbf{g}$ masonry walls; h Stress states for samples under compression load as a function of slenderness ( adapted from Van Mier et al. [36]) (note: black triangles indicate regions of triaxial confinement)

out to assess the compressive strength $\left(f_{\mathrm{m}}\right)$ of masonry units as recommended by codified procedures (Figs. 2c and 3g). The specimen reference adopts the format $W x y$, where $x$ indicates ambient-dry (D) or wet (W) and $y$ represents the specimen sequence ( $\mathrm{a}, \mathrm{b}, \mathrm{c}$, etc.). From the total of 12 wall specimens built, 9 were tested in compression and, as mentioned before, 3 untested walls were used to extract cylindrical cores. Six of the tested walls in compression were selected for direct comparison considering the influence of moisture on the response. These were WDa, WDb, WDc in dry conditions and WWa, WWb, WWc in wet conditions. The others included a pilot test or had eccentric failures (dry specimen WDd and wet specimen WWd) which are described briefly at the end of Sect. 3.3.

The walls were built on a flat horizontal surface following the procedures described in BS EN 1052-1 [57], respectively. The specimens had both horizontal and vertical lime mortar joints with an average thickness of $14.4 \pm 1.4 \mathrm{~mm}$. This was needed to adjust the uneven sizes of the bricks. The bricks were 
laid as received from the manufacturer without any conditioning or soaking in water prior to placing the mortar, which may have had an influence on the porosity of the fresh mortars. After the last course of bricks was laid, the specimens were kept in laboratory conditions. A plastic sheet was used to cover the specimens at early curing and the specimens were tested within a week at an age of 42-47 days. Three days before testing, the wall surfaces in contact with the loading plates were capped with a high-strength cement slurry with a ratio $1: 1$, and relatively heavy steel plates of $6.5 \mathrm{~kg}$ were placed above the fresh cement slurry to ensure planeness of the loading surface.

Due to the relatively low height of the specimens $(403 \pm 5.1 \mathrm{~mm})$, immersion to $3 / 5$ of depth corresponding to 3 courses of bricks, enabled full capillary absorption of water. Visual inspection indicated that the top bricks that were not immersed in water were saturated. To obtain the moisture distribution across the specimen, a supplementary wall was built and subjected to the same conditioning and curing procedure. Prior to the immersion of $3 / 5$ of wall depth in water (courses i-iii in Fig. 2c), each brick was marked. After $48 \mathrm{~h}$, the wall was dismantled, and each brick and mortar joints were weighed. To obtain the moisture content, all components were dried in an oven for $6 \mathrm{~h}$ at $60{ }^{\circ} \mathrm{C}$ and for at least $18 \mathrm{~h}$ at $105^{\circ} \mathrm{C}$ until the sample mass was largely constant. The moisture distribution results indicated that the same moisture content of $10.7 \% \pm 0.2 \mathrm{wt}$ was consistently obtained in all five brick courses (i-v), irrespective of whether they were submersed in water or not, due to capillary absorption. The moisture content was therefore shown to be evenly distributed across the specimen.

\subsection{Testing arrangements and instrumentation}

The specimens were tested in a four-post Instron $3500 \mathrm{kN}$ machine and the testing arrangement included top and bottom high strength steel transfer plates, with the actuator at the top. As illustrated in Fig. 2a-c, two displacement transducers were employed around the specimens to record the axial displacement between the machine base and the top transfer plate. These were used as a secondary measurement system, along with displacement recordings provided by the machine and the data from the digital image correlation (DIC) system, as described below.

DIC is a non-contact system which offers a high level of accuracy and practicality compared to conventional mechanical instrumentation at ambient and elevated temperature [58-60]. It consists of two light-weight CMOS cameras with USB 3.0 interface for distances up to $25 \mathrm{~m}$. The high sensitivity cameras have a resolution of $2.3 \mathrm{Megapixel}$ at $100 \mathrm{~Hz}$ frame rate. These are connected to a controller which also acts as a data acquisition system. As part of the preparation process, the specimens were firstly painted in white, and then carefully speckled with $0.5-2.0 \mathrm{~mm}$ black dots to create a high-contrast black-white pattern. The size of the black dots depended on the size of the specimen and distance between the cameras and speckled surface.

Prior to testing, a calibration procedure was undertaken by adjusting iteratively the aperture, ambient lighting and camera focus, while taking photos of a calibration plate adjacent to the specimen face. This was required to allow the post-processing software to compute the distance between the cameras and the specimen, and ultimately to compute the surface strain vector fields. A frequency of $0.2 \mathrm{~Hz}$ for recording data was chosen to acquire a sufficiently large pool of data to minimise possible scatter [61]. After testing, the DIC data were further processed to obtain deformation vector fields. From these, surface strains or deformations were obtained from assigned virtual gauges with various lengths depending on the specimen size and brick layout.

As mentioned in Sects. 2.1 and 2.2, standardised compressive tests on brick units and flexural tests on notched half-bricks were carried out and strains or crack opening were obtained from DIC data. For the compressive brick tests shown in Fig. 2a, vertical $50 \mathrm{~mm}$ gauges and horizontal $25 \mathrm{~mm}$ gauges were assigned to assess the axial and the lateral strain, respectively. For the cylindrical cores (Fig. 2b), a vertical gauge of $70 \mathrm{~mm}$ and horizontal gauges of $15 \mathrm{~mm}$ at mid-height of the specimen were used to determine axial and lateral strains, respectively. To obtain the axial strain of the small walls (Fig. 2c), two vertical gauges of $170 \mathrm{~mm}$ were used, whilst to determine the lateral strains, a horizontal gauge of $240 \mathrm{~mm}$ was used to assess lateral strains [57]. 


\section{Experimental results}

\subsection{Stress-strain behaviour}

\subsubsection{Mortars}

As mentioned in Sect. 2.1.1, cubic $(50 \times 50 \times$ $50 \mathrm{~mm})$ samples and prismatic $(25 \times 25 \times$ $150 \mathrm{~mm})$ samples were used for compressive and flexural strength assessments, respectively. Cube tests were carried out both in ambient-dry and wet conditions following the conditioning procedure described before. The resulting average compressive strength of the mortar in ambient-dry conditions was $1.29 \pm 0.09 \mathrm{MPa}$. Figure 4, which depict the stressstress strain curves of lime mortars show that moisture reduces the compressive strength and the elastic modulus by about $55 \%$ and $43 \%$, respectively, compared to those of ambient-dry mortar samples. Slightly lower strengths than expected for a mortar incorporating NHL5 lime were obtained, primarily due to relatively high temperatures $\left(28 \pm 2{ }^{\circ} \mathrm{C}\right)$ and low humidity levels during the setting period. The ambient-dry flexural strengths obtained from the four-point tests were $0.28 \pm 0.01 \mathrm{MPa}$, which is about $20 \%$ of the corresponding compressive strength.

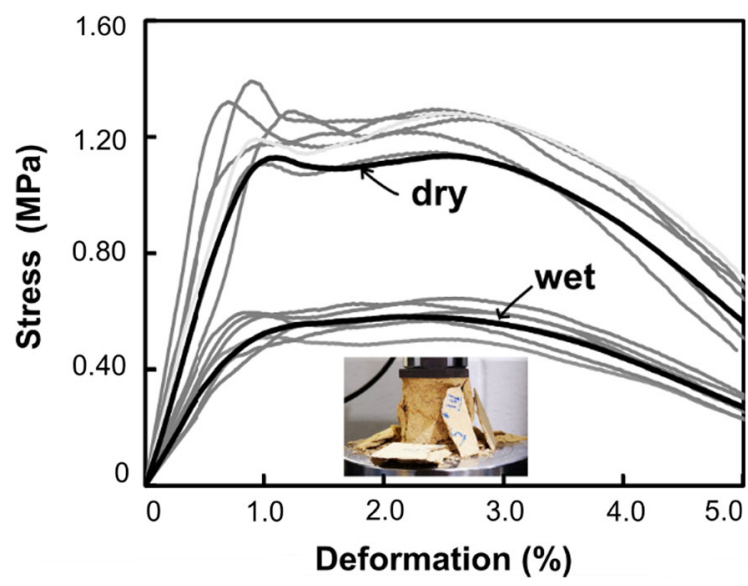

Fig. 4 Stress deformation response of NHL5 mortar under ambient-dry and wet conditions (note that the deformations were assessed from displacement values recorded by the testing machine)
Fig. 5 Brick compressive strength perpendicular to the bed joints: a dry, b wet; parallel to the bed joint $\mathbf{c}$ dry, $\mathbf{d}$ wet; Stressstrain response of core specimens-single core: e dry, f wet; two cores stacked $\mathbf{g}$ dry, $\mathbf{h}$ wet; two cores with mortar joint in the middle $\mathbf{i}$ dry, $\mathbf{j}$ wet; two cores with mortar joints at their top, middle and bottom: $\mathbf{k}$ dry, $\mathbf{h}$ wet (notes: $\sigma$-stress, $\varepsilon$ - strain)

\subsubsection{Brick units}

The stress-strain $(\sigma-\varepsilon)$ curves illustrated in Fig. 5a-d were assessed from digital image correlation (DIC) data, as described in detail in Sect. 2 above. Grey curves depict test results and the black curve is their average. Negative strain values depict lateral strain, whilst positive strain values are for axial strains. As shown in Fig. 5a-b, the compressive strengths of brick units perpendicular to the testing bed, assessed from a minimum of three samples, were 9.00 MPa in ambient-dry (PPD) conditions and 8.86 MPa in wet conditions (PPW). Tests on bricks parallel to the testing bed, depicted in Fig. 5c-d, showed that the average compressive strength, also obtained from a minimum of three tests, was $15.5 \mathrm{MPa}$ in ambient-dry conditions (PRD) and 15.6 in wet conditions (PRW).

Hence, the moisture had virtually no effect on the specimen strength, whilst the difference in strength obtained from the two testing arrangements is due to the different confinement levels developed within the material, as discussed before. These standardised tests enable a direct comparison with the tests on cored elements, as described below. The average flexural strength of the tested bricks was 1.55 MPa for samples in ambient-dry conditions (BBD) and 1.41 MPa in wet conditions (BBW). The reduction in strength due to moisture was associated with a softer post-peak response.

\subsubsection{Brick-only cylindrical cores}

A total of 20 cylindrical brick-only specimens extracted from untested walls and bricks, as described in Sect. 2 above, were prepared for uniaxial testing. As mentioned before, in order to ensure that a uniaxial stress state develops at the centre of the specimen, the height-to-diameter ratio of 10 cylinders was $h /$ $d \geq 2$.0. The remaining 10 cylinders had $h / d=1.0$ and were tested to assess the influence of $h / d$ and triaxial confinement effects on the strength of the brick 


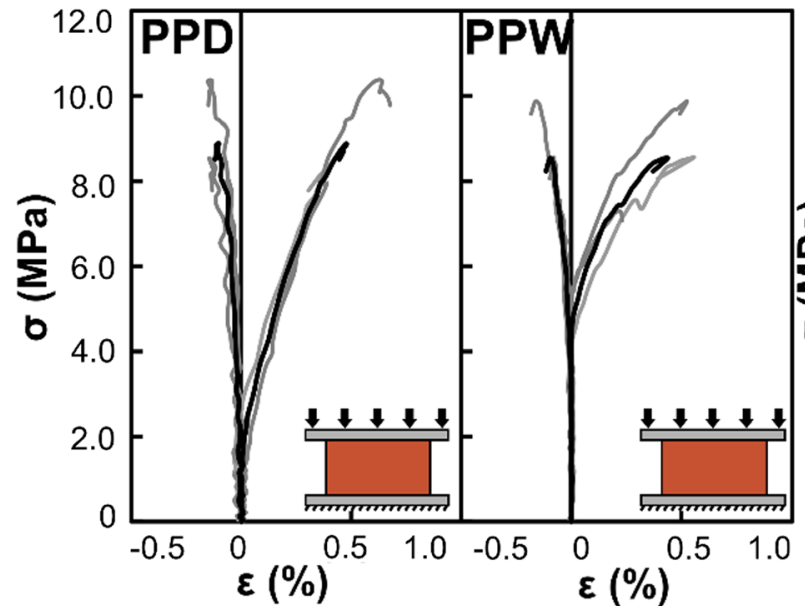

(a)

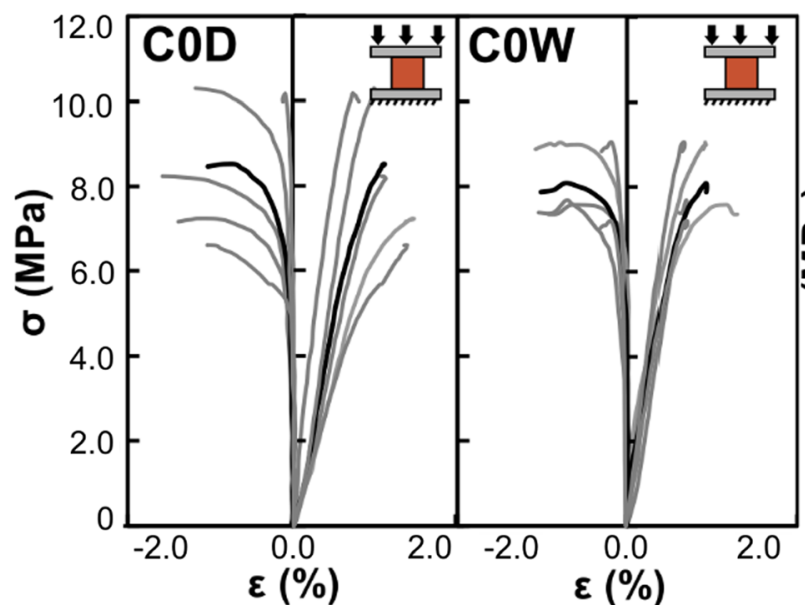

(e)

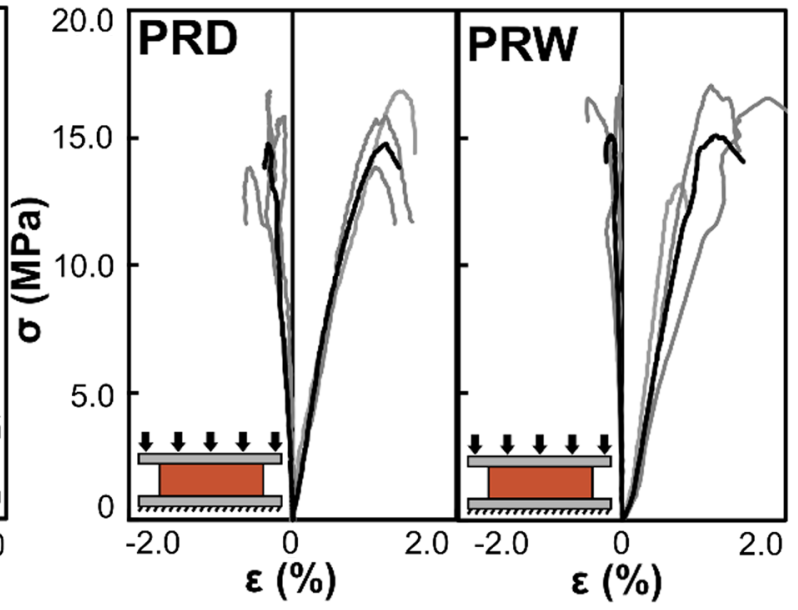

(c)

(d)

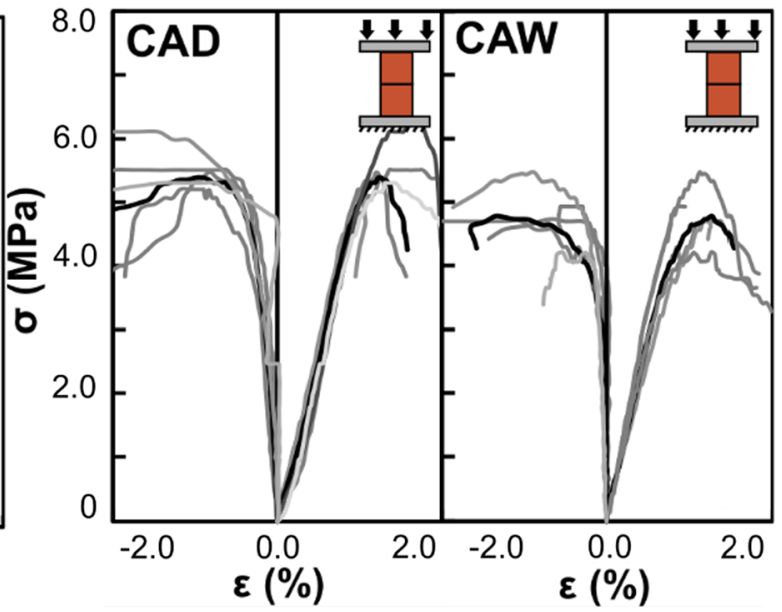

(g)

(h)

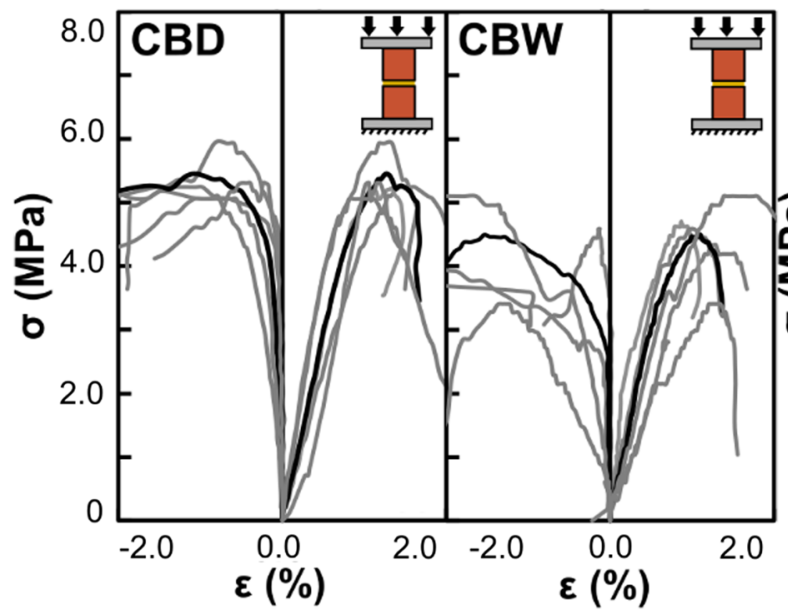

(i)

(j)

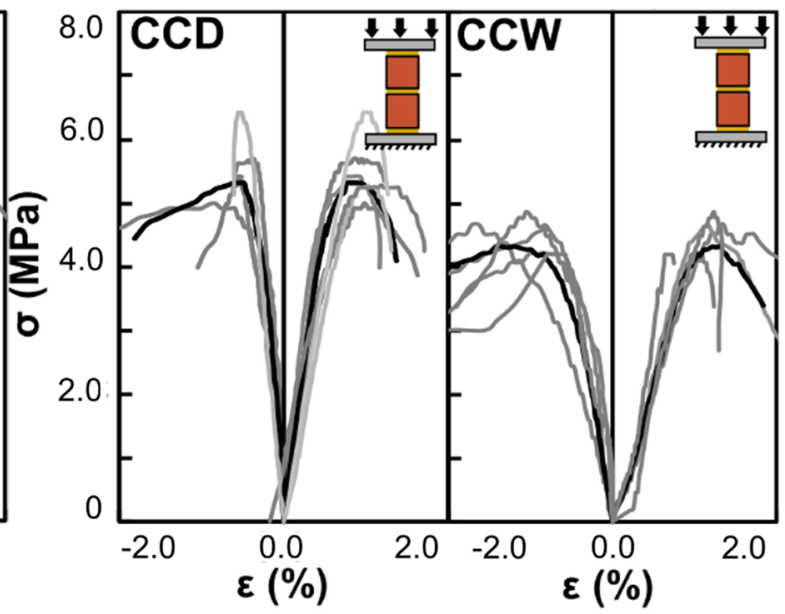

(k)

(I) 
materials, as well as for comparison with standardised tests on brick units described in Sect. 3.1.1. A heightto-diameter ratio of $h / d=2.0-3.0$ and a sample diameter above $50 \mathrm{~mm}$ is recommended for such tests [56, 62].

Figure $5 \mathrm{e}-\mathrm{h}$ depicts the stress-strain $\sigma-\varepsilon$ response of the brick-only tested cores obtained from processed DIC data, in which continuous grey curves represent three of the five tests from which the minimum and maximum were disregarded. The continuous black curve is the average. Additionally, Fig. 6a-b illustrates the specimen configurations as well as representative failure patterns after testing, also obtained from processed DIC data. The complete details, including the strength, strains at crushing and elastic modulus are given in Table 1. The elastic modulus was determined in the $0.3-0.5 \times f_{\mathrm{m}}$ stress range, where $f_{\mathrm{m}}$ is the specimen strength as the $\sigma-\varepsilon$ curves exhibited relatively linear response.

The wet single-brick specimens (COW) had an average $E_{\mathrm{m}}=1185 \mathrm{MPa}$, whilst for those in ambientdry conditions $(\mathrm{COD}) E_{\mathrm{m}}=1133 \mathrm{MPa}$. Group CAW

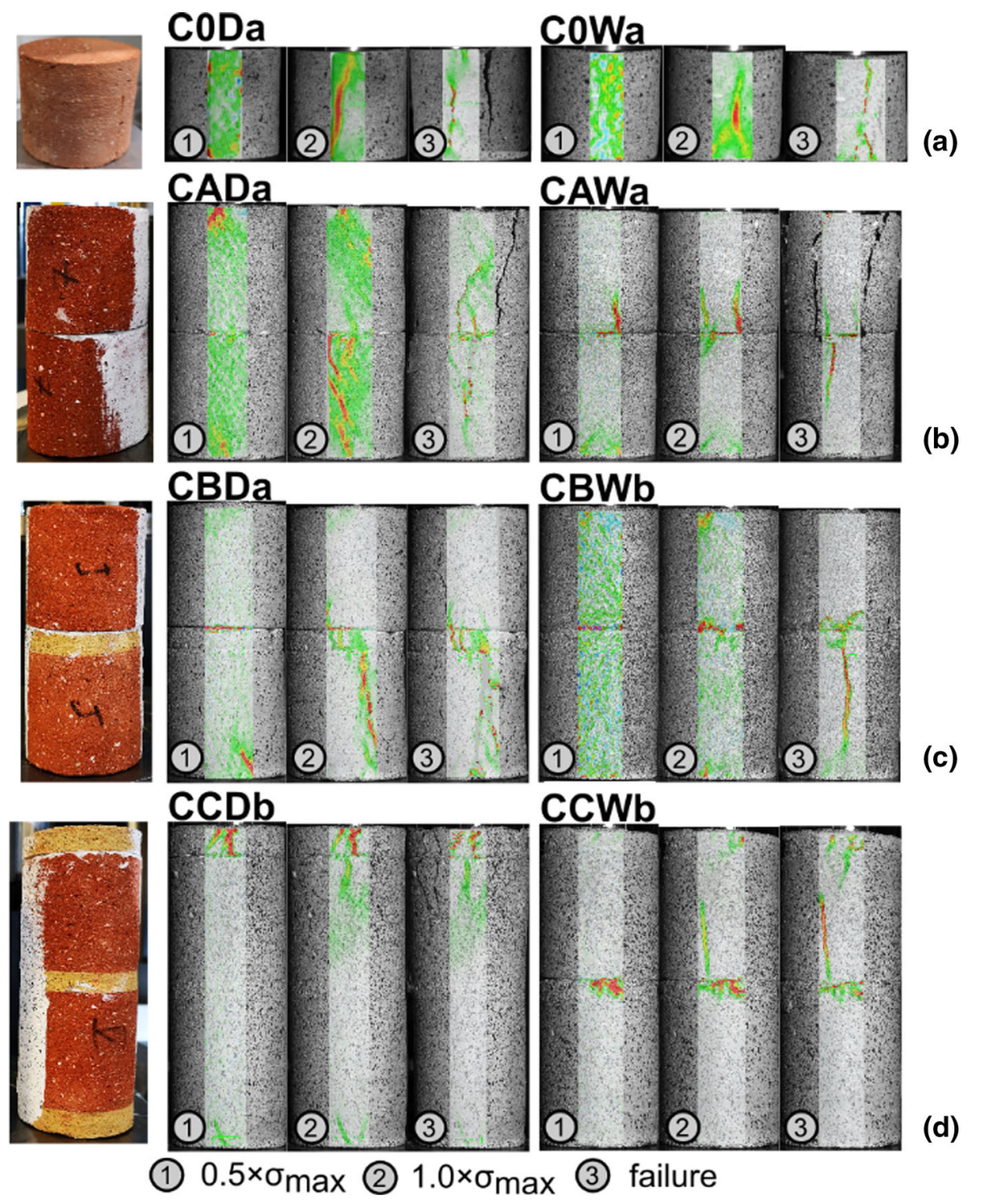

Fig. 6 Cylindrical specimens and fracture propagation: a single core, $\mathbf{b}$ two cores stacked, $\mathbf{c}$ two cores with a mortar joint at the middle; d two cores with mortar joints at their top, middle and bottom

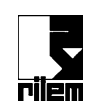


Table 1 Results from cylindrical tests

\begin{tabular}{|c|c|c|c|c|c|c|c|c|c|}
\hline & $f_{\mathrm{m}}(\mathrm{MPa})$ & $\varepsilon_{1}(\%)$ & $\varepsilon_{2}(\%)$ & $E_{\mathrm{m}}(\mathrm{MPa})$ & & $f_{\mathrm{m}}(\mathrm{MPa})$ & $\varepsilon_{1}(\%)$ & $\varepsilon_{2}(\%)$ & $E_{\mathrm{m}}(\mathrm{MPa})$ \\
\hline $\mathrm{CODa}$ & 8.23 & 1.08 & -1.58 & 962 & COWa & 9.03 & 0.91 & -0.79 & 1297 \\
\hline $\mathrm{CODb}$ & 7.24 & 1.47 & -1.15 & 857 & $\mathrm{COWb}$ & 7.66 & 0.68 & -0.72 & 1101 \\
\hline CODc & 10.18 & 0.80 & -0.12 & 1462 & COWc & 7.56 & 1.13 & -0.58 & 928 \\
\hline CODd & 6.60 & 1.31 & -1.01 & 923 & $\mathrm{COWd}$ & 9.06 & 0.67 & -0.16 & 1428 \\
\hline CODe & 10.29 & 0.94 & -1.15 & 1463 & CoWe & 7.20 & 0.69 & -0.17 & 1170 \\
\hline Average & 8.51 & 1.12 & -1.00 & 1133 & Average & 8.10 & 0.82 & -0.48 & 1185 \\
\hline CADa & 5.51 & 1.44 & -0.78 & 633 & CAWa & 4.70 & 1.17 & -1.05 & 572 \\
\hline $\mathrm{CADb}$ & 5.20 & 1.01 & -0.83 & 576 & $\mathrm{CAWb}$ & 4.73 & 1.24 & -0.65 & 474 \\
\hline CADc & 5.47 & 1.20 & -0.80 & 714 & CAWc & 4.93 & 0.95 & -0.56 & 632 \\
\hline CADd & 6.24 & 1.54 & -0.97 & 629 & CAWd & 5.47 & 1.13 & -0.88 & 718 \\
\hline CADe & 5.30 & 1.31 & -0.75 & 549 & CAWe & 4.21 & 1.26 & -0.53 & 512 \\
\hline Average & 5.54 & 1.30 & -0.83 & 620 & Average & 4.81 & 1.15 & -0.73 & 582 \\
\hline CBDa & 5.24 & 1.40 & -0.97 & 519 & CBWa & 4.33 & 1.22 & -2.68 & 522 \\
\hline $\mathrm{CBDb}$ & 5.21 & 1.27 & -1.05 & 624 & $\mathrm{CBWb}$ & 4.71 & 0.87 & -0.18 & 552 \\
\hline CBDc & 5.93 & 1.18 & -0.83 & 796 & CBWc & 4.59 & 1.04 & -0.15 & 716 \\
\hline CBDd & 5.31 & 1.19 & -0.44 & 681 & CBWd & 3.41 & 1.22 & -1.24 & 413 \\
\hline CBDe & 5.06 & 1.12 & -0.98 & 727 & CBWe & 5.10 & 1.38 & -1.29 & 368 \\
\hline Average & 5.35 & 1.23 & -0.85 & 669 & Average & 4.43 & 1.15 & -1.11 & 514 \\
\hline $\mathrm{CCDa}$ & 5.71 & 0.95 & -0.40 & 1105 & CCWa & 4.67 & 1.31 & -1.42 & 571 \\
\hline $\mathrm{CCDb}$ & 5.43 & 0.93 & -0.51 & 1090 & $\mathrm{CCWb}$ & 4.66 & 1.12 & -0.81 & 740 \\
\hline CCDc & 5.00 & 0.97 & -0.83 & 831 & $\mathrm{CCWc}$ & 4.23 & 0.98 & -0.83 & 658 \\
\hline CCDe & 5.29 & 1.02 & -0.64 & 727 & CCWe & 4.88 & 1.24 & -1.05 & 670 \\
\hline CCDf & 6.43 & 1.01 & -0.54 & 824 & CCWf & 4.20 & 0.72 & -0.60 & 754 \\
\hline Average & 5.57 & 0.98 & -0.58 & 915 & Average & 4.53 & 1.07 & -0.94 & 679 \\
\hline
\end{tabular}

$f_{\mathrm{m}}$-element compressive strength, $\varepsilon_{1}$-axial strain at crushing, $\varepsilon_{2}$-lateral strain at crushing, $E_{\mathrm{m}}$-elastic modulus

specimens had an $E_{\mathrm{m}}=582 \mathrm{MPa}$, whilst for CAD $E_{\mathrm{m}}=620 \mathrm{MPa}$ indicating a reduction of $6.2 \%$ due to high moisture. In terms of compressive strength, both dry and wet single-brick $(h / d \approx 1.0)$ specimens had similar strengths (i.e. 8.51 MPa for COD and 8.10 for COW, respectively). Specimens with $h / d \geq 2.0$ in ambient-dry conditions (CAD) had strengths in the range of $f_{\mathrm{m}}=5.54 \mathrm{MPa}$, whilst those in wet conditions (CAW) were around $f_{\mathrm{m}}=4.81 \mathrm{MPa}$. As observed, the reduction in compressive strength due to moisture was in the range of $6 \%$ for specimens with $h / d \approx 1.0$ and $13 \%$ for those with $h / d \geq 2.0$, depending on the specimen configuration. Additionally, the increase in strength between ambient-dry COD $(h /$ $d \approx 1.0)$ and $\operatorname{CAD}(h / d \approx 2.0)$ was by $53 \%$, and between wet COW and CAW was by $68 \%$, respectively. This indicates a difference of at least $53 \%$ between the uniaxial material properties and those in confined conditions.

\subsubsection{Masonry cylindrical cores}

The presence of a mortar layer between brick cylinders resulted in a reduction in $E_{\mathrm{m}}$ of $23 \%$ between ambientdry and wet $\left(E_{\mathrm{m}, \mathrm{d}}=669 \mathrm{MPa}\right.$ for $\mathrm{CBD}$, and $E_{\mathrm{m}, \mathrm{w}-}$ $=514 \mathrm{MPa}$ for $\mathrm{CBW}$ ). The highest reduction of stiffness was observed for the third group of wet specimens CCW which had an elastic stiffness $26 \%$ lower than the ambient-dry counterparts CCD with $E_{\mathrm{m}, \mathrm{w}}=679 \mathrm{MPa}$ and $E_{\mathrm{m}, \mathrm{d}}=915 \mathrm{MPa}$, respectively. The softer response of CCW samples occurred due to initial crushing in the wet mortar layers, rather than the brick elements. Additionally, the $\sigma-\varepsilon$ curves for wet specimens indicate a larger variability with the number of mortar layers (Fig. 5e-1). 
Specimens CBD and CCD with $h / d \geq 2.0$ in ambient-dry conditions had strengths in the range of $f_{\mathrm{m}}=5.35-5.57 \mathrm{MPa}$ with minimal influence from the presence of mortar compared with CAD. On the other hand, the wet specimens (CBW, CCW) had $f_{\mathrm{m}-}$ $=4.43-4.53 \mathrm{MPa}$ with a higher standard deviation than the ambient-dry counterparts. A direct comparison between the average $\sigma-\varepsilon$ for ambient-dry and wet cases (CBD versus CBW) gives a similar level of reduction in terms of crushing strain (7\%). Moreover, for $\mathrm{CCD}$ versus $\mathrm{CCW}$, an increase in crushing strain is observed (9\%). This can be explained by early dilation of the mortar layers in comparison to the brick elements due to their relatively soft nature when high moisture levels exist. The characteristic behaviour of each component can be represented by means of the volumetric strain development, as explained in detail below.

\subsection{Volumetric response}

In addition to the $\sigma-\varepsilon$ from Fig. 5, the volumetric strain $\left(\varepsilon_{\mathrm{vol}}\right)$ is illustrated against the stress-to-strength ratio $\left(\sigma / f_{\mathrm{m}}\right)$ in Fig. 7 as an average of the test curves for each configuration. The parameter $\varepsilon_{\mathrm{vol}}$ of a member subjected to compression can be assessed by the sum of three strain components $\left(\sum \varepsilon_{i}\right.$, where $\mathrm{i}=1,2,3$ is the corresponding axis) [63]. For cylindrical specimens, $\varepsilon_{\mathrm{vol}}$ consists of the axial strain $\varepsilon_{\mathrm{axial}}$ $\left(\varepsilon_{1}\right)$ plus twice the lateral strain, $2 \times \varepsilon_{\text {lateral }}\left(\varepsilon_{2}+\varepsilon_{3}\right)$. Considering that axial strain is positive, and lateral

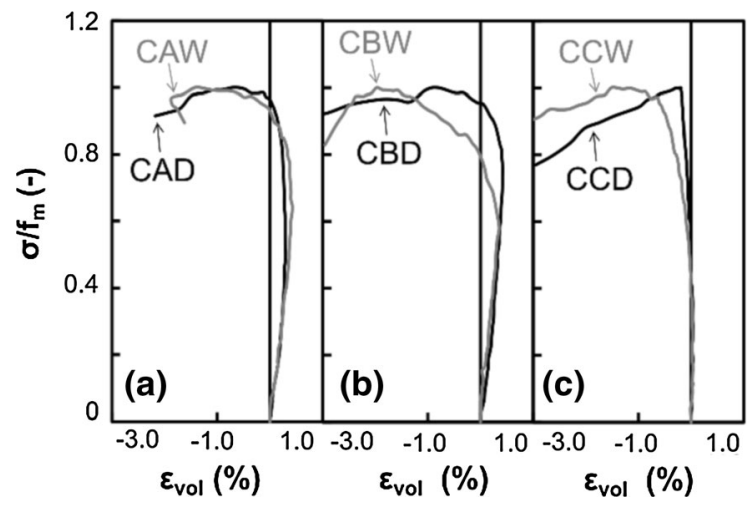

Fig. 7 Average volumetric response a two cores stacked$\mathrm{CAD}$ versus $\mathrm{CAW}$, b two cores with a mortar joint at the middle-CBD versus CBW, $\mathbf{c}$ two cores with mortar joints at their top, middle and bottom-CCD versus CCW.(notes: $\sigma / f_{\mathrm{m}}-$ stress-to-strength ratio, $\varepsilon_{\mathrm{vol}}$ - volumetric strain) strain is negative, a positive $\varepsilon_{\mathrm{vol}}$ represents volume reduction (contraction/compaction), whilst a negative $\varepsilon_{\mathrm{vol}}$ indicates volume increase (expansion/dilation).

As illustrated in Fig. 7a, the $C A x$ specimens which consisted of two brick cylinders stacked together had a similar response, with $\varepsilon_{\mathrm{vol}}$ increasing gradually up to about $50 \%$ of the peak, indicating volume reduction, and then becomes negative indicating dilation near the peak strength. As the number of mortar layers increased from 1 to 3 layers ( $C B x$ versus $C C x$ specimens), the transition between contraction to dilation occurred at lower stress-to-strength $\sigma / f_{\mathrm{m}}$ ratios, particularly for wet specimens (Fig. 7b). More importantly, for $C C x$ specimens, $\varepsilon_{\mathrm{vol}}$ becomes negative (Fig. 7c) at relatively low $\sigma / f_{\mathrm{m}}$ below $40 \%$, with a significantly higher dilation occurring for $\mathrm{CCW}$ specimens in comparison with CCD. The higher dilation of the mortar layers in comparison to that of the brick cores arises from the lower elastic modulus of the mortar compared to that of the brick. This effect is more visible for wet specimens for which the wet mortar has an elastic modulus $43 \%$ lower than that of its ambient-dry counterpart (Fig. 4).

In Fig. 8, the volumetric strain $\varepsilon_{\mathrm{vol}}$ for each component is plotted against $\sigma / f_{\mathrm{m}}$. Figure 8a,b depict the response of the ambient-dry CADa and wet CAWa samples, which consisted of two stacked brick cylinders. In both cases, the $\sigma / f_{\mathrm{m}}-\varepsilon_{\mathrm{vol}}$ responses have similar shapes indicating that both cylinders worked together as a unit initially contracting at different $\sigma / f_{\mathrm{m}}$ as a function of the conditioning developing dilation. This synergetic response is also indicated by the crack patterns which continue from top to bottom of the sample (Fig. 6b). In contrast, samples with one layer between the two brick cylinders (CBDa and $\mathrm{CBWb}$ ) had a distinct response. With the increase in $\sigma / f_{\mathrm{m}}$, the mortar developed dilation earlier than the brick components, and this effect is stronger for the wet $\mathrm{CBWb}$ specimen in comparison to the ambient-dry counterpart (CBDa).

For specimens with intermediate, top and bottom mortar layers, the response is governed by mortar dilation, whilst the two brick components are in contraction until near the peak (Fig. 8e,f). For the ambient-dry specimen CCD2, a sequential dilation behaviour following the main load path through the weaker components is observed. The highest dilation is developed by the top mortar layer, followed by that located at mid-height of the specimen, whilst the 


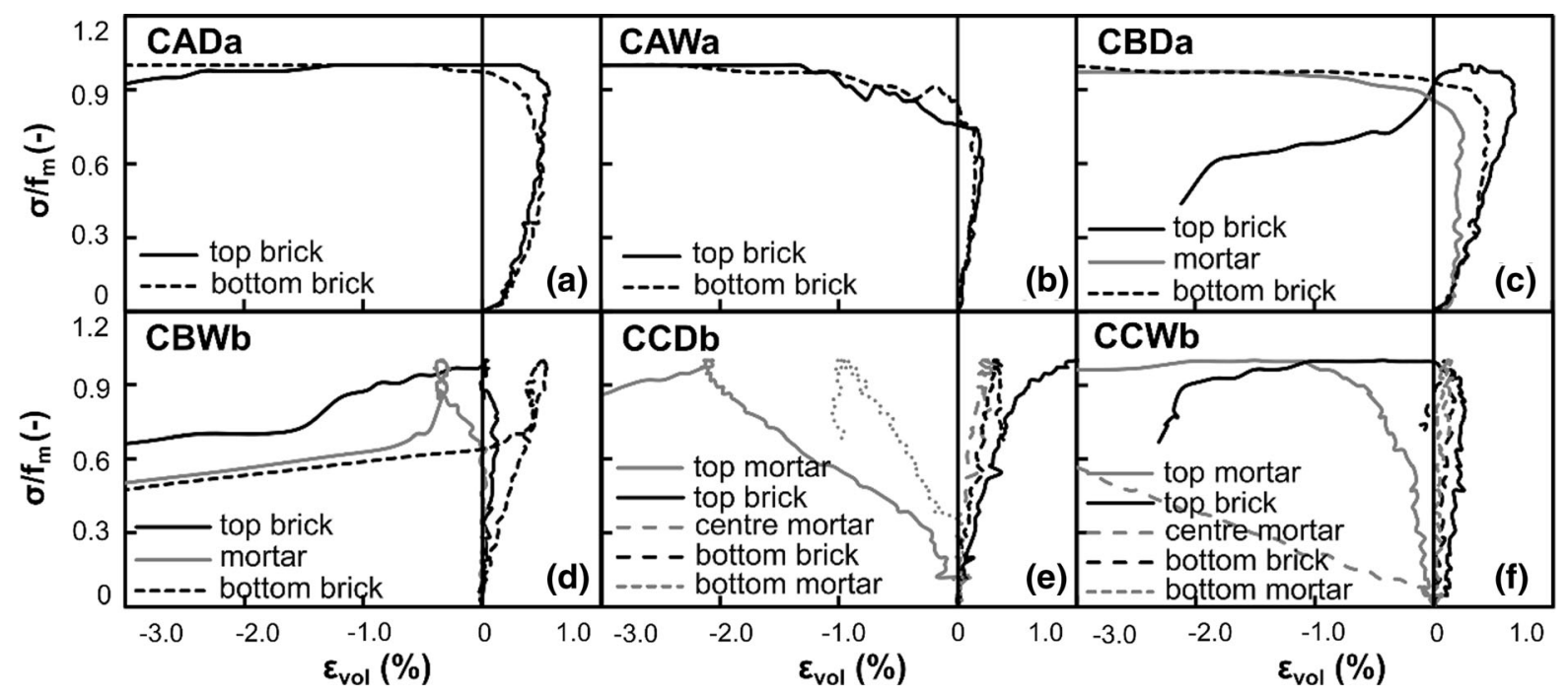

Fig. 8 Volumetric response of selected samples: two cores stacked a CADa—dry, b CAWa—wet; two cores with a mortar joint at the middle $\mathbf{c} \mathrm{CBDa}-\mathrm{dry}, \mathbf{d ~ C B W b}$ - wet; two cores with

bottom layer is in a contraction regime. On the other hand, the response of the wet CCW3 specimen is governed by the intermediate mortar layer which acts as the weak link in the multi-layer sample. The response of the intermediate mortar layer is responsible for the low elastic modulus of the CCW samples compared to the CCD counterparts.

\subsection{Walls in compression}

Tests on small wall specimens were carried out to assess the compressive strength $\left(f_{\mathrm{m}}\right)$ of masonry units as recommended by codified procedures. From the nine members tested, six (i.e. WDa-c and WWa-c) were selected for direct comparison considering the influence of moisture on the response. The others included a pilot test or had eccentric failures (i.e. WDd and WWd) that are described briefly at the end of this section. The failure of the brick masonry specimens was due to crushing of brick components and mortar joints which typically initiated at a vertical brickmortar interface. Due to the inherent variability of the brick dimensions and implicitly of the cast in situ mortar layers, failure initiated at different locations within the specimens.

Figure 9 illustrates the crack patterns, as obtained from DIC data, as well as the sequence of crack development with applied axial displacement. For mortar joints at their top, middle and bottom e $\mathrm{CCDb}-$ dry, f $\mathrm{CCWb}$-wet(notes: $\sigma / f_{\mathrm{m}}$-stress-to-strength ratio, $\varepsilon_{\mathrm{vol}}$ volumetric strain)

example, in Specimens WDa and WWa, cracking initiated at the vertical mortar-brick interface located at the bottom of the specimen, at the centre of the first brick course. In contrast, failure in Specimens WDc and $\mathrm{WWb}$ initiated at the top, at the interface located at the centre of the fifth brick course. In Specimens WWc and WDb, cracking started at the third and fourth brick course at the vertical interface located on the right side of the specimen. The crack patterns after failure can be divided into two main groups: specimens in which cracking developed mainly at the centre (i.e. WDc) and members with two fracture surfaces occurring on the left and right sides (e.g. WDa and WWa). In all cases, the fracture surfaces initiated at vertical brickmortar interfaces and passed vertically through the adjacent bricks.

Regardless of the failure mode, the capacity achieved, particularly for the dry specimens (WDy) had similar values with an average of $220 \mathrm{kN}$ and a standard deviation of $9.9 \mathrm{kN}$ (Table 2). A similar average strength of $212 \mathrm{kN}$ was obtained for the wet (WWy) elements, yet with a significantly higher standard deviation of $29.5 \mathrm{kN}$. This can also be observed from the load-displacement curves illustrated in Fig. 10, in which continuous grey curves depict test results, whilst the continuous black curves are their average. The displacement values were obtained from a vertical gauge placed along the height 

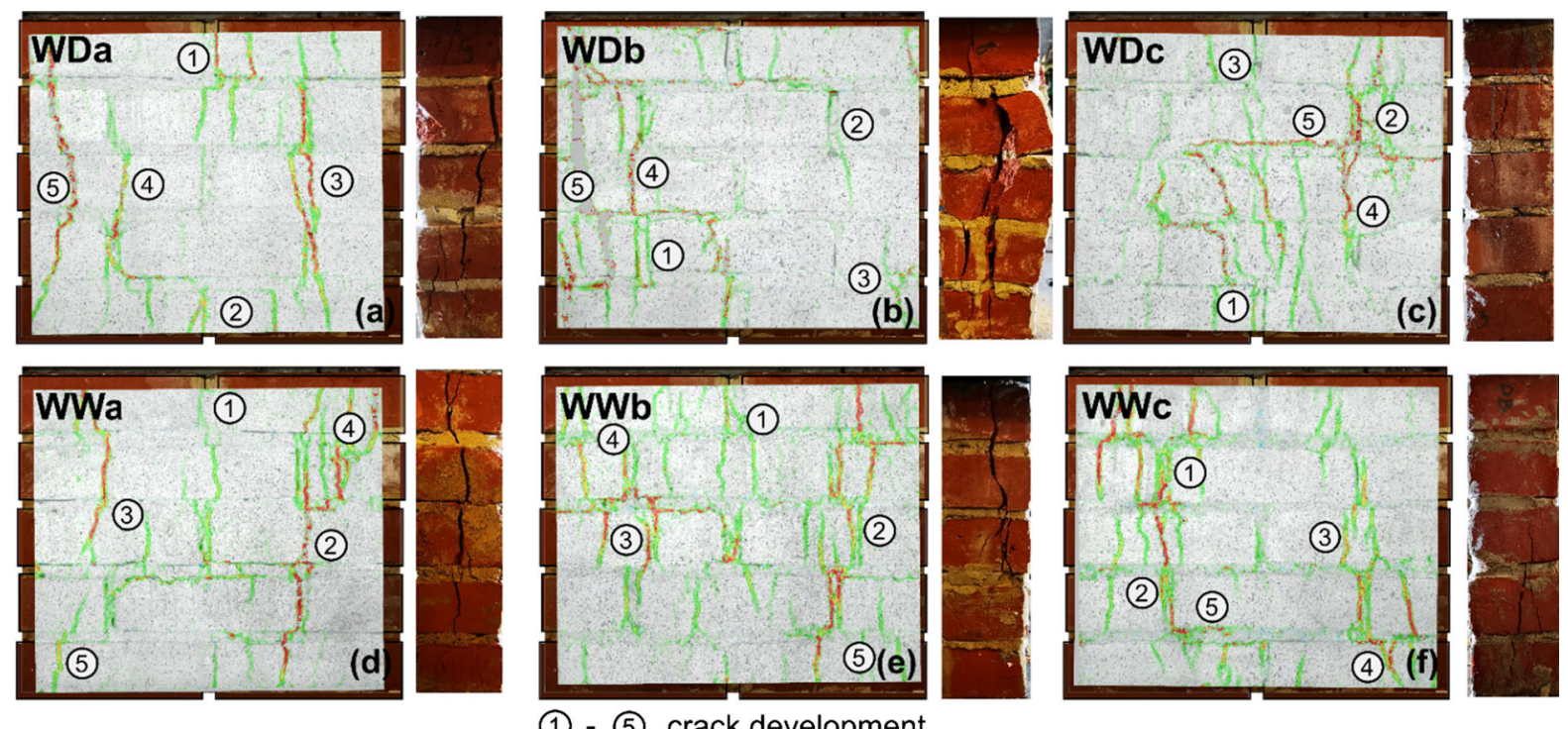

Fig. 9 Ultimate crack patterns of masonry walls: a WDa, b WDb, $\mathbf{c} \mathrm{WDc}, \mathbf{d} \mathrm{WWa}, \mathbf{e} \mathrm{WWb}, \mathbf{f} \mathrm{WWc}$;

Table 2 Test results on walls

\begin{tabular}{|c|c|c|c|c|c|c|c|c|c|c|}
\hline & $b_{1}(\mathrm{~mm})$ & $h(\mathrm{~mm})$ & $b_{2}(\mathrm{~mm})$ & $P_{\max }(\mathrm{kN})$ & $\delta_{\mathrm{u}}(\mathrm{mm})$ & $\mathrm{K}(\mathrm{N} / \mathrm{mm})$ & $f_{\mathrm{m}}(\mathrm{MPa})$ & $\varepsilon_{1}(\%)$ & $\varepsilon_{2}(\%)$ & $E_{\mathrm{m}}(\mathrm{MPa})$ \\
\hline WDa & 471 & 408 & 110 & 227 & 5.83 & 44,494 & 4.39 & 0.474 & -0.504 & 1674 \\
\hline WDb & 474 & 403 & 110 & 228 & 5.37 & 48,850 & 4.37 & 0.997 & -0.790 & 582 \\
\hline WDc & 471 & 399 & 110 & 210 & 5.59 & 41,306 & 4.08 & 0.938 & -0.937 & 748 \\
\hline WDd & 473 & 398 & 110 & 187 & 6.69 & 36,782 & 3.59 & 0.785 & -0.680 & 594 \\
\hline Average (WDa-c) & - & - & - & 222 & 5. 60 & 44,883 & 4.28 & 0.803 & -0.744 & 1001 \\
\hline Average (WDa-d) & - & - & - & 213 & 5.87 & 42,858 & 4.11 & 0.798 & -0.728 & 899 \\
\hline WWa & 472 & 404 & 110 & 187 & 4.83 & 43,705 & 3.61 & 0.750 & -0.241 & 605 \\
\hline $\mathrm{WWb}$ & 474 & 399 & 110 & 245 & 5.54 & 54,281 & 4.73 & 0.866 & -0.752 & 1159 \\
\hline WWc & 471 & 397 & 110 & 226 & 5.66 & 45,736 & 4.37 & 0.812 & -0.412 & 676 \\
\hline WWd & 471 & 403 & 110 & 174 & 8.18 & 34,739 & 3.35 & 0.650 & -1.120 & 274 \\
\hline Average (WWa-c) & - & - & - & 219 & 5.34 & 47,908 & 4.24 & 0.809 & -0.469 & 813 \\
\hline Average (WWa-d) & - & - & - & 208 & 6.05 & 44,615 & 4.02 & 0.769 & -0.631 & 678 \\
\hline
\end{tabular}

$\mathrm{b}_{1}$ - element width, $\mathrm{h}$-element height, $\mathrm{b}_{2}$-element thickness, $\mathrm{P}_{\max }$-peak load, $\delta_{\mathrm{u}}$-displacement at peak, $f_{\mathrm{m}}$-element compressive strength, $\mathrm{K}$ - specimen stiffness, $\varepsilon_{1}$ - axial strain at crushing, $\varepsilon_{2}$ - lateral strain at crushing, $\mathrm{E}_{\mathrm{m}}$-elastic modulus

of the specimen, whilst the load is the value recorded by the testing machine. These curves show a typical brittle behaviour with softening directly after the peak load is reached.

The average displacements at peak load were $5.73 \mathrm{~mm}$ for WDy members and $4.94 \mathrm{~mm}$ for WWy members, whilst their average stiffness was relatively similar with a difference of about $6 \%$. For these specimens, the high moisture conditions affected to a lower extent the capacity and response of brick masonry walls in comparison to the influence observed from tests on cylindrical specimens with aspect ratios of $h / d>2.0$. The masonry walls had an aspect ratio $h /$ $d<0.85$ which is between the aspect ratio of brick units tested perpendicular (PPy) to the bed face $(h /$ $d<0.48)$ and cores (COy) with $h / d=1.0$. Due to the triaxial confinement effects, for these cases, the difference in strength between wet and air-dry 

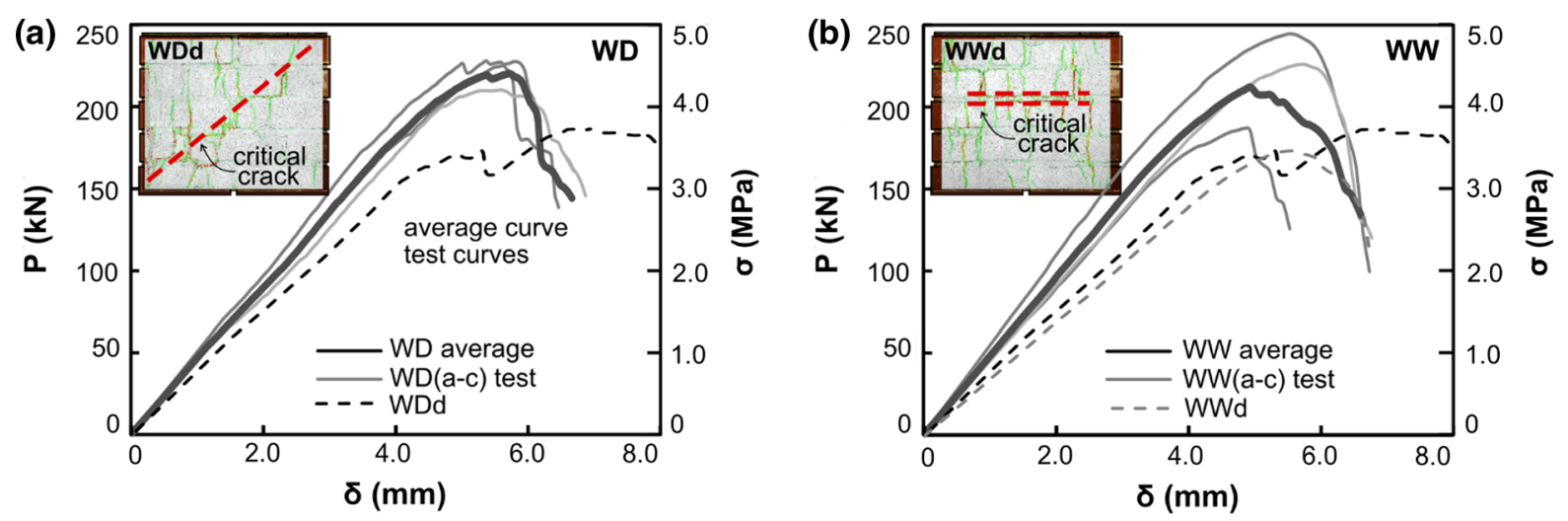

Fig. 10 Stress-strain response of walls in compression: a WD, b WW (note: $\mathrm{P}$-applied load, $\sigma$ —stress, $\delta$-displacement)

specimens was $1-5 \%$. Similar effects would have been developed in the small masonry walls, therefore, a relatively low variation in compression capacity between wet and ambient-dry elements occurred.

Close inspection of the stress-strain $(\sigma-\varepsilon)$ results determined from DIC measurements indicated a high variability with respect to the lateral-to-axial strain ratio $\varepsilon_{2} / \varepsilon_{1}$ ratio, primarily due to the inherent composite behaviour of the masonry unit and variation in crack kinematics. As shown in Fig. 10, for ambientdry specimens (WDy) $f_{\mathrm{m}}=4.28 \mathrm{MPa}$, whilst for those in wet conditions (WWy) $f_{\mathrm{m}}=4.24 \mathrm{MPa}$, indicating an insignificant reduction in $f_{\mathrm{m}}$ of only $1 \%$. It is important to note that these observations are limited to this particular configuration and require further future validation using a higher number of samples combined with a wider set of parametric assessments.

The average elastic modulus $E_{\mathrm{m}}$ was assessed at the stress range of $30-50 \%$ of the peak, as the $\sigma-\varepsilon$ response in this range was linear. As indicated in Table 2, a reduction in $E_{\mathrm{m}}$ from 1001 to $813 \mathrm{MPa}$ was observed due to the high moisture conditions between WDy and WWy specimens, which corresponds to about $19 \%$. A direct comparison between the test results on cylindrical elements and walls shows that the latter offers a lower bound of $f_{\mathrm{m}}$, which is about $20 \%$ and $7 \%$ lower for ambient-dry and wet specimens, respectively. This indicates that standardised compression tests (e.g. based on EN 1052-1) on walls can be a viable conservative alternative for design as these would offer a lower bound of compressive strength. In contrast, for the assessment of masonry structures with particular focus on the nonlinear response which require detailed uniaxial stress-strain curves as an input, tests on cylindrical specimens with $h / d \approx 2.0$ would be more representative. In such tests, uniaxial stress states develop at the specimen midheight and capture in a reliable manner the uniaxial constitutive response than in the other cases investigated herein.

As mentioned before, two of the tests developed failures governed by eccentric behaviour. Specimen WDd reached a peak load of $P_{\max }=187 \mathrm{kN}$, whilst WWd had a $P_{\max }=174 \mathrm{kN}$ and, as shown in Fig. 10a, $\mathrm{b}$, with an inherent lower stiffness in comparison to average curves of Specimens WDa-c and WWa-c. These values are $15 \%$ and $18 \%$ lower than the average $\mathrm{P}_{\max }$ of ambient-dry and wet specimens failing under concentric compression. For WDd, failure initiated at the bottom right corner of the wall and at ultimate had a diagonal pattern, indicating the presence of some inplane bending, which is mainly attributed to the uneven brick sizes and inherent variability in the mortar layer thickness. On the other hand, although the fracture patterns of WWa prior to peak resemble those from Fig. 9b,c of specimens under concentric behaviour, at the peak a longitudinal crack was observed at the interfaces between the third course of bricksmortar and mortar-fourth course of bricks. This crack, shown at the top right-hand side of Fig. 10b, developed due to some out-of-plane bending occurring during testing.

\section{Comparative findings and results}

Moisture within masonry walls can have a detrimental effect on buildings and may undermine their long-term 
durability and integrity $[64,65]$. This occurs primarily due to the porosity and absorption rate properties of the bricks [66]. As masonry elements are intrinsically composite, besides brick and mortar properties, brickmortar bond interactions govern their mechanical response. Brick absorption properties affect the bond strength as well as the moisture transfer between components, and also control the setting and hydration properties of the mortar [65].

The tests described in this paper show that core masonry samples with mortar joints and $h / d>2.0$, (CBW and $\mathrm{CCW}$ ) in wet conditions, having a moisture content of about $10 \%$ by weight had a lower compressive strength of about $14-18 \%$ in comparison to those in ambient-dry conditions (CBD and CBW) with a moisture content of about $2.5 \%$ by weight. Close inspection of other results from the literature, on masonry elements made of solid clay bricks and lime mortar $[8,18]$ or cement mortar [6], indicate that the compressive strength is relatively constant for values of moisture between $0 \%$ and 2-3\%, which correspond to oven-dry and air-dry conditions, respectively. Beyond this value, a gradual reduction in compression strength in the range of $15 \%$ occurs with the increase in moisture up to values around 10-13\%. It is worth noting that the moisture content is dependent on the porosity of the material, a parameter which governs the total water absorption. Hence, the above comments are specific to the masonry components investigated in this paper as well as in the cited references $[6,8,18]$.

Test results on brick-only single core cylinders $(h /$ $d \approx 1.0$ ), without mortar joints, indicated a decrease in compression strength of only $6 \%$ between ambient-dry and wet conditions (Specimens COD and COW, respectively), as higher confinement levels exist in the element compared with brick-only core cylinders with $h / d \approx 2.0$ (CAD and CAW). The increase in strength between the two stacked core specimens $(h /$ $d \approx 2.0$ ) and single core cylinders $(h / d \approx 1.0)$, was in the range of $58 \%$ for dry elements, and around $68 \%$ for wet elements. A direct comparison between standardised brick tests parallel to the bed joints (PR) and those on cylinders $(\mathrm{C} 0)$, that had the same specimen height $\mathrm{h} \approx 69 \mathrm{~mm}$, showed that the brick compressive strength was $81-92 \%$ higher than that of the core.

Tests on bricks perpendicular to the bed joint (PP) and those on two-stacked cores (CA) also indicated higher compressive strength in the range of $67-84 \%$ for bricks in comparison to the brick-only cores. The above comments aim at quantifying how triaxial confinement produced by the restraint imposed by the loading plates affects the specimen compressive strength. These results may be used as an estimate of uniaxial compressive strength of brick materials based on standardised unit tests. Parametric assessments incorporating a wider range of bricks and mortar types would be required to provide more general recommendations.

The observations from the tests described in this paper suggest that the uniaxial material strength required for non-linear assessment of masonry structures are much lower than those of brick units due to confinement effects mobilised in the latter. Tests on full units with relatively small thickness, similar to the size of bricks from this study, and typically found in historic masonry structures [52], indicate that the effect of confinement could lead to unreliable strengths, hence results from direct tests on bricks laid horizontally can be misleading [66]. Accordingly, brick material strengths should be assessed from cylindrical specimens with $h / d \approx 2.0$ or, alternatively, conversion factors to account for confinement may be used.

Detailed digital image correlation (DIC) data showed that, for cylindrical masonry samples with mortar joints (i.e. $\mathrm{CBD} / \mathrm{CBW}$ and $\mathrm{CCD} / \mathrm{CCW}$ ), with the increase in stress-to-strength ratios the mortar developed dilation earlier than the brick components. This effect was found to be more significant for the wet specimens in comparison to the ambient-dry counterparts. It has already been shown that wet HNL mortar samples typically exhibit lower mechanical strengths than those in air-dry conditions [6, 67]. In such cases, when the brick stiffness is higher than that of the mortar, the mortar is in a triaxial compression state, whilst the bricks are in axial compression and lateral tension. As shown in Fig. 6. Failure initiates due to loss of bond between bricks and mortar [6] and is associated with mortar cracking and spalling [60].

As shown in many studies, the behaviour of dried porous building materials such as clay bricks, mortar and concrete is highly dependent on the level of confinement. The reduction of strength due to moisture (wet or saturated) in unconfined conditions is due to fluid pressure enabling earlier pore wall fracture than in ambient-dry conditions [68]. As a result, the unconfined compressive strength reduces with higher degrees of saturation, and strength reductions of up to 
$72 \%$ between dry and saturated state can occur [69]. The increase in the strength of dry and lightly wet materials with confinement pressure occurs due to the cohesion and friction between stacking grains [70]. The response of significantly wet and saturated materials at high confining pressures is similar to that of undrained, non-cohesive and saturated granular stacking sequences, where a volume decrease generates an increase in pore pressure [71].

For an element with a high aspect ratio $(h / d)$, a uniaxial stress state develops at mid-height, where the dilation is unrestricted [54, 55]. For significantly wet and saturated conditions, the pore pressure increase due to compression loading would produce an earlier pore wall fracture and, at sample level, a lower strength compared to its corresponding dry or lightly wet counterpart. In contrast, for elements with very low aspect ratios $(h / d)$, the lateral dilation is delayed due to the triaxial confinement within the specimen. Although an increase in pore pressure is expected when confinement exists, and pore wall cracking would occur earlier, this may be counterbalanced by the confining pressure which would prevent the cracks from opening. It can be seen that this is a coupled elastic-plastic fluid-saturated porous material problem, and the balance between the two thrusts (i.e. mechanical loading and fluid pressure) depends on a threshold at which air-porosity is closed and the material is fully saturated [70, 72].

When comparing the uniaxial material tests on cylindrical masonry cores with $h / d \approx 2.0(\mathrm{CBD} / \mathrm{CBW}$ and $\mathrm{CCD} / \mathrm{CCW}$ ) to those on masonry walls with $h /$ $d=0.85(\mathrm{WD} / \mathrm{WW})$, it is shown that the reduction in compressive strength between ambient-dry and wet for the latter was only $1 \%$, particularly due to triaxial confinement effects resulting from the testing arrangement. These reduction levels were also obtained for tested samples with $h / d \leq 1.00$. The lower strength in masonry wall tests in comparison to cylindrical masonry cores may also result from a larger variability in terms of mechanical properties of slop moulded bricks. Such trends have been observed before in comparative tests on dry prismatic specimens and small walls [73]. Besides the inherent variations in material properties within a specimen, the type and level of loading have an influence on the response of dry and wet masonry specimens. In this respect, it is worth noting that large scale walls tests, which are underway as part of the same project [39], subjected to realistic levels of combined axial and lateral loading, indicate a significant reduction of about $10 \%$ in ultimate strength and about $25 \%$ in member stiffness, under wet conditions. The differences in mechanical properties between ambient-dry and wet masonry elements therefore need to be assessed with due consideration of the expected confinement level and loading configuration.

\section{Conclusions}

This paper described an experimental investigation into the fundamental mechanical properties of masonry elements incorporating fired-clay bricks and hydraulic lime mortars under ambient-dry and wet conditions, corresponding to $48 \mathrm{~h}$ of submersion in water. A detailed account of more than 50 tests was given. In addition to complementary brick and mortar characterisation tests, two types of masonry specimens were tested: cylindrical cores and wall elements in compression. Apart from conventional load and displacement measurements, the use of digital image correlation techniques enabled a detailed assessment of the influence of moisture on the constitutive response and mechanical properties of masonry components. The key observations are outlined below.

The reduction in compressive strength due to moisture was in the range of 5\% for brick-only cylindrical core specimens with height-to-depth $(h / d)$ ratios around 1.0 , and $13 \%$ for brick-only cylinders with $h / d$ around 2.0. Due to high confinement levels, specimens with $h / d$ ratios around 1.0 developed a similar elastic modulus regardless of the conditioning. A direct comparison between standardised brick tests parallel to the bed joints and those on brick-only cylinders with $h / d=1.0$ showed that the compressive strength of the brick is $81-92 \%$ higher than that of the cylinder, whilst the strength of bricks tested perpendicular to the bed joint was about $67-84 \%$ higher than that of brick-only cylinders with $h / d=2.0$.

The results show that the strength mobilised in brick units in masonry structures is much higher than the uniaxial material properties as a function of the brick and mortar joint thickness, their relative stiffness and bond properties. Moreover, the effects of moisture seem to be less significant in the presence of confinement. The above comments aim at quantifying how triaxial confinement produced by the restraint imposed 
by the loading plates affects the specimen compressive strength. These results may be used as an estimate of uniaxial compressive strength of brick materials based on standardised unit tests.

Detailed measurements of the volumetric response showed that brick-only cylinders with $h / d=2.0$ made of two stacked cores had a synergetic response indicated by the crack patterns that propagated in an uninterrupted manner through the two components, both in ambient-dry and wet conditions. In masonry brick-mortar-brick elements, due to the relatively softer nature of mortar layers in the presence of high moisture levels, the compression response was governed by early dilation of the mortar. Consequently, the difference in compressive strength and elastic moduli between wet and dry masonry cylinders was significantly higher than that of wet and dry brick-only cylinders, with similar aspect ratio.

The failure of masonry wall elements subjected to compression was due to crushing of the brick components and mortar joints that initiated at a vertical brick-mortar interface. For this specific arrangement, an insignificant difference in strength of only $1 \%$ was obtained between the wet and ambient-dry conditions. Such tests can be useful for conservative design, but for the assessment of historic structures with particular focus on modelling the nonlinear response, tests on cylindrical specimens with aspects ratios above two are more representative as these tests would capture more reliably the uniaxial material strength properties. The conclusions drawn from the results obtained in this study are evidently specific to the materials and configurations investigated, and more general recommendations would necessitate further parametric assessments incorporating a wider range of brick and mortar characteristics as well as geometry and loading arrangements.

Acknowledgements The authors would like to acknowledge the support provided by the technical staff of the Structures Laboratories at Imperial College London, particularly $\mathrm{Mr}$. T. Stickland.

Funding The study was supported by the Arts and Humanities Research Council of the UK Research and Innovation agency, within the project "Interdisciplinary approach for the management and conservation of UNESCO World Heritage Site of Historic Cairo-Application to Al-Ashraf Street", Grant No. AH/R00787X/1.

\section{Compliance with ethical standards}

Conflict of interest The authors declare that they have no conflict of interest.

Open Access This article is licensed under a Creative Commons Attribution 4.0 International License, which permits use, sharing, adaptation, distribution and reproduction in any medium or format, as long as you give appropriate credit to the original author(s) and the source, provide a link to the Creative Commons licence, and indicate if changes were made. The images or other third party material in this article are included in the article's Creative Commons licence, unless indicated otherwise in a credit line to the material. If material is not included in the article's Creative Commons licence and your intended use is not permitted by statutory regulation or exceeds the permitted use, you will need to obtain permission directly from the copyright holder. To view a copy of this licence, visit http://creativecommons.org/licenses/by/4.0/.

\section{References}

1. Cotic P, Jaglicic Z, Niederleithinger E, Effner U, Kruschwitz S, Trela C, Bosiljkov V (2013) Effect of moisture on the reliability of void detection in brickwork masonry using radar, ultrasonic and complex resistivity tomography. Mater Struct 46(10):1723-1735. https://doi.org/10.1617/s11527012-0011-3

2. Gentilini C, Franzoni E, Graziani G, Bandini S (2015) Mechanical properties of fired-clay brick masonry models in moist and dry conditions. Key Eng Mater 624: 307-312. https://doi.org/10.4028/www.scientific.net/KEM.624.307

3. Giaccone D, Santamaria U, Corradi M (2020) An experimental study on the effect of water on historic brickwork masonry. Heritage 3(1):29-46. https://doi.org/10.3390/ heritage 3010003

4. Guizzardi M, Derome D, Mannes D, Vonbank R, Carmeliet J (2016) Electrical conductivity sensors for water penetration monitoring in building masonry materials. Mater Struct 49(7):2535-2547. https://doi.org/10.1617/s11527-0150666-7

5. Hamid AA, Orphy M (2012) Durability of historic brick masonry. In: Conference on structural analysis of historic constructions, pp 1836-1843

6. Sathiparan N, Rumeshkumar U (2018) Effect of moisture condition on mechanical behavior of low strength brick masonry. J Build Eng 17:23-31. https://doi.org/10.1016/j. jobe.2018.01.015

7. Amade AM, Martin JV, Colville J (2004) The effect of moisture on compressive strength and modulus of brick masonry. In Proceedings of 13th international brick and block masonry conference. Amsterdam. PMid, vol 15043442.

8. Witzany J, Cejka T, Zigler R (2010) The effect of moisture on significant mechanical characteristics of masonry. Statybines Konstrukcijos ir Technologijos 2(3):79-85

9. Gokceoglu C, Aksoy H (2000) New approaches to the characterization of clay-bearing, densely jointed and weak 
rock masses. Eng Geol 58(1):1-23. https://doi.org/10.1016/ S0013-7952(00)00032-6

10. Gautam TP, Shakoor A (2013) Slaking behavior of claybearing rocks during a one-year exposure to natural climatic conditions. Eng Geol 166:17-25. https://doi.org/10.1016/j. enggeo.2013.08.003

11. Liu Y, Cai Y, Huang S, Guo Y, Liu G (2019) Effect of water saturation on uniaxial compressive strength and damage degree of clay-bearing sandstone under freeze-thaw. Bull Eng Geol Environ. https://doi.org/10.1007/s10064-01901686-w

12. Tiennot M, Mertz JD, Bourgès A (2017) Influence of anisotropic microcracking due to swelling on the fracture toughness of a clay-bearing sandstone. Rock Mech Rock Eng 50(11):2861-2870. https://doi.org/10.1007/s00603017-1273-4

13. Gratchev I, Pathiranagei SV, Kim DH (2019) Strength properties of fresh and weathered rocks subjected to wetting-drying cycles. Geomech Geophys Geo-Energy GeoResour 5(3):211-221. https://doi.org/10.1007/s40948-01900104-5

14. Erguler ZA, Ulusay R (2009) Water-induced variations in mechanical properties of clay-bearing rocks. Int J Rock Mech Min Sci 46(2):355-370. https://doi.org/10.1016/j. ijrmms.2008.07.002

15. Vásárhelyi B (2003) Some observations regarding the strength and deformability of sandstones in dry and saturated conditions. Bull Eng Geol Env 62(3):245-249. https:// doi.org/10.1007/s10064-002-0186-x

16. Mazzotti C, Sassoni E, Pagliai G (2014) Determination of shear strength of historic masonries by moderately destructive testing of masonry cores. Constr Build Mater 54:421-431. https://doi.org/10.1016/j.conbuildmat.2013. 12.039

17. Gentilini C, Franzoni E, Bandini S, Nobile L (2012) Effect of salt crystallisation on the shear behaviour of masonry walls: an experimental study. Constr Build Mater 37:181-189. https://doi.org/10.1016/j.conbuildmat.2012. 07.086

18. Franzoni E, Gentilini C, Graziani G, Bandini S (2015) Compressive behaviour of brick masonry triplets in wet and dry conditions. Constr Build Mater 82:45-52. https://doi. org/10.1016/j.conbuildmat.2015.02.052

19. Hanykýř V, Kloužková A, Bouška P, Vokáč M (2009) Ageing of historical ceramics. Acta Geodyn Geomater 6(1):59-66

20. Foraboschi P, Vanin A (2014) Experimental investigation on bricks from historical Venetian buildings subjected to moisture and salt crystallization. Eng Fail Anal 45:185-203. https://doi.org/10.1016/j.engfailanal.2014.06.019

21. Franzoni E, Pigino B, Leemann A, Lura P (2014) Use of TEOS for fired-clay bricks consolidation. Mater Struct 47(7):1175-1184. https://doi.org/10.1617/s11527-0130120-7

22. Karagiannis N, Karoglou M, Bakolas A, Krokida M, Moropoulou A (2017) Drying kinetics of building materials capillary moisture. Constr Build Mater 137:441-449. https://doi.org/10.1016/j.conbuildmat.2017.01.094

23. Rirsch E, Zhang Z (2010) Rising damp in masonry walls and the importance of mortar properties. Constr Build Mater
24(10):1815-1820. https://doi.org/10.1016/j.conbuildmat. 2010.04.024

24. Roberts TM, Hughes TG, Dandamudi VR, Bell B (2006) Quasi-static and high cycle fatigue strength of brick masonry. Constr Build Mater 20(9):603-614. https://doi. org/10.1016/j.conbuildmat.2005.02.013

25. TC 203-RHM (Jan Erik Lindqvist) Repair mortars for historic masonry. Testing of hardened mortars, a process of questioning and interpreting. Materials and Structures (2009) 42: 853. https://doi.org/10.1617/s11527-008-9455-x

26. Cuezva S, García-Guinea J, Fernandez-Cortes A, Benavente D, Ivars J, Galan JM, Sanchez-Moral S (2016) Composition, uses, provenance and stability of rocks and ancient mortars in a Theban Tomb in Luxor (Egypt). Mater Struct 49(3):941-960. https://doi.org/10.1617/s11527-015-0550-5

27. Papayianni I, Pachta V (2015) Experimental study on the performance of lime-based grouts used in consolidating historic masonries. Mater Struct 48(7):2111-2121. https:// doi.org/10.1617/s11527-014-0296-5

28. TC 203-RHM (Caspar Groot). Repair mortars for historic masonry: Performance requirements for renders and plasters. Materials and Structures, 45, pp.1277-1285. https:// doi.org/10.1617/s11527-012-9916-0

29. Ince C, Carter MA, Wilson MA (2015) The water retaining characteristics of lime mortar. Mater Struct 48(4):1177-1185. https://doi.org/10.1617/s11527-0130224-0

30. Hughes JJ, Taylor AK (2005) Compressive and flexural strength testing of brick masonry panels constructed with two contrasting traditionally produced lime mortars. In: RILEM technical committee international workshop on repair mortars for historic masonry, pp 26-28

31. Carcangiu G, Casti M, Desogus G, Meloni P, Ricciu R (2015) Microclimatic monitoring of a semi-confined archaeological site affected by salt crystallisation. J Cult Herit 16(1):113-118. https://doi.org/10.1016/j.culher.2014. 02.001

32. Janssen H, Derluyn H, Carmeliet J (2012) Moisture transfer through mortar joints: a sharp-front analysis. Cem Concr Res 42(8):1105-1112. https://doi.org/10.1016/j.cemconres. 2012.05.004

33. Cultrone G, Sebastian E, Huertas MO (2005) Forced and natural carbonation of lime-based mortars with and without additives: mineralogical and textural changes. Cem Concr Res 35(12):2278-2289. https://doi.org/10.1016/j.cemcon res.2004.12.012

34. Pavía S, Hanley R (2010) Flexural bond strength of natural hydraulic lime mortar and clay brick. Mater Struct 43(7):913-922. https://doi.org/10.1617/s11527-009-9555-2

35. Pavía S, Treacy E (2006) A comparative study of the durability and behaviour of fat lime and feebly-hydraulic lime mortars. Mater Struct 39(3):391-398. https://doi.org/ $10.1617 / \mathrm{s} 11527-005-9033-4$

36. Scolforo MJ, Browne H (1996) Acquisition and properties of brick for historic structure preservation and rehabilitation. In: Standards for preservation and rehabilitation. ASTM International. https://doi.org/10.1520/STP15447S

37. Drougkas A, Roca P, Molins C (2016) Compressive strength and elasticity of pure lime mortar masonry. Mater Struct 49(3):983-999. https://doi.org/10.1617/s11527-015-0553-2 
38. Moriconi G, Castellano MG, Collepardi M (1994) Mortar deterioration of the masonry walls in historic buildings. A case history: Vanvitelli's Mole in Ancona. Mater Struct 27(7):408-414. https://doi.org/10.1007/BF02473445

39. Elghazouli A, Butler A, Mourad S, Cheeseman C, Elyamani A (2018) Interdisciplinary approach for the management and conservation of UNESCO World Heritage Site of Historic Cairo. Application to Al-Ashraf Street. UK Research and Innovation, viewed 7 July 2019, https:/gtr.ukri.org/ projects?ref=AH\%2FR00787X\%2F1

40. Dizhur D, Giaretton M, Giongo I, Walsh KQ, Ingham JM (2019) Material property testing for the refurbishment of a historic URM building in Yangon. Myanmar J Build Eng 26:100858. https://doi.org/10.1016/j.jobe.2019.100858

41. BS EN 459-2. Building lime: test methods. British Standards Institution, UK.

42. Secil Argamassas, Natural hydraulic lime (NHL) - the binder. Available at: https://www.secilargamassas.pt/ uploads/documentos/Ficha_Tecnica_NHL_5.pdf. Accessed 10 Nov 2019

43. Xu S, Wang J, Sun Y (2015) Effect of water binder ratio on the early hydration of natural hydraulic lime. Mater Struct 48(10):3431-3441. https://doi.org/10.1617/s11527-0140410-8

44. BS EN 13139:2013 Aggregates for mortar. British Standards Institution, UK.

45. Flower DJ, Sanjayan JG (2007) Green house gas emissions due to concrete manufacture. Int $\mathrm{J}$ Life Cycle Assess 12(5):282. https://doi.org/10.1065/lca2007.05.327

46. BS EN 1015-2: Methods of test for mortar for masonry-Part 2: Bulk sampling of mortars and preparation of test mortars. British Standards Institution, UK.

47. Bompa DV, Elghazouli AY (2020) Properties of hydraulic lime mortars subjected to dry-wet cycles. Technical report, Imperial College London, UK

48. BS EN 1015-3:1999 Methods of test for mortar for masonry - Part 3: Determination of consistence of fresh mortar (by flow table). British Standards Institution, UK.

49. BS EN 1015-11:1999 Methods of test for mortar for masonry - Part 11: Determination of flexural and compressive strength of hardened mortar. British Standards Institution, UK.

50. Egernsund Tegl, Chelmer Red Imperial. Available at: https://www.egernsund-tegl.com/products/bricks/270-2.2. 07-chelmer-red-imperial. Accessed 10 Nov 2019

51. BS EN 771-1:2011+A1:2015. Specification for masonry units Part 1: Clay masonry units. British Standards Institution, UK.

52. Atzeni C, Massidda L, Sanna U (1997) Roman bricks in a marine environment. Mater Struct 30(2):120-125. https:// doi.org/10.1007/BF02486313

53. Stefanidou M, Papayianni I, Pachta V (2015) Analysis and characterization of Roman and Byzantine fired bricks from Greece. Mater Struct 48(7):2251-2260. https://doi.org/10. 1617/s11527-014-0306-7

54. Van Mier JGM, Shah SP, Arnaud M, Balayssac JP, Bascoul A, Choi S, Dasenbrock D, Ferrara G, French C, Gobbi ME, Karihaloo BL (1997) Strain-softening of concrete in uniaxial compression. Mater Struct 30(4):195-209. https://doi. org/10.1007/BF02486177
55. Kotsovos MD (1983) Effect of testing techniques on the post-ultimate behaviour of concrete in compression. Materiaux et construction 16(1):3-12. https://doi.org/10.1007/ BF02474861

56. Oliveira DV, Lourenço PB, Roca P (2006) Cyclic behaviour of stone and brick masonry under uniaxial compressive loading. Mater Struct 39(2):247-257. https://doi.org/10. 1617/s11527-005-9050-3

57. BS EN 1052-1:1999 Methods of test for masonry - Part 1: Determination of compressive strength. British Standards Institution, UK.

58. Xu B, Bompa DV, Elghazouli AY, Ruiz-Teran AM, Stafford PJ (2018) Behaviour of rubberised concrete members in asymmetric shear tests. Constr Build Mater 159:361-375. https://doi.org/10.1016/j.conbuildmat.2017.10.091

59. Bompa DV, Elghazouli AY (2019) Elevated temperature characteristics of steel reinforcement incorporating threaded mechanical couplers. Fire Saf J 104:8-21. https://doi. org/10.1016/j.firesaf.2018.12.006

60. Ravula MB, Subramaniam KV (2017) Experimental investigation of compressive failure in masonry brick assemblages made with soft brick. Mater Struct 50(1):19. https://doi.org/10.1617/s11527-016-0926-1

61. LaVision - DaVis digital image correlation software https:// www.lavision.de/en/products/davis-software/index.php. Accessed 10 Nov 2019

62. Fairhurst CE, Hudson JA (1999) Draft ISRM suggested method for the complete stress-strain curve for intact rock in uniaxial compression. Int $\mathrm{J}$ Rock Mech Min Sci 36(3):279-289

63. Choi E, Jeon JS, Cho BS, Park K (2013) External jacket of FRP wire for confining concrete and its advantages. Eng Struct 56:555-566. https://doi.org/10.1016/j.engstruct. 2013.05.019

64. Walker R, Pavía S, Dalton M (2016) Measurement of moisture content in solid brick walls using timber dowel. Mater Struct 49(7):2549-2561. https://doi.org/10.1617/ s11527-015-0667-6

65. Maheri MR, Sherafati MA (2012) The effects of humidity and other environmental parameters on the shear strength of brick walls: evaluation of field test data. Mater Struct 45(6):941-956. https://doi.org/10.1617/s11527-011-9809-7

66. Aubert JE, Maillard P, Morel JC, Al-Rafii M (2016) Towards a simple compressive strength test for earth bricks. Mater Struct 49(5):1641-1654. https://doi.org/10.1617/ s11527-015-0601-y

67. Garijo L, Azenha M, Ramesh M, Lourenço PB, Ruiz G (2019) Stiffness evolution of natural hydraulic lime mortars at early ages measured through EMM-ARM. Constr Build Mater 216:405-415. https://doi.org/10.1016/j.conbuildmat. 2019.04.258

68. Walsh JB (1981) Effect of pore pressure and confining pressure on fracture permeability. Int J Rock Mech Mining Sci Geomech Abst 18(5):429-435. https://doi.org/10.1016/ 0148-9062(81)90006-1

69. Shakoor A, Barefield EH (2009) Relationship between unconfined compressive strength and degree of saturation for selected sandstones. Environ Eng Geosci 15(1):29-40. https://doi.org/10.2113/gseegeosci.15.1.29

70. Vu XH, Malecot Y, Daudeville L, Buzaud E (2009) Experimental analysis of concrete behavior under high 
confinement: effect of the saturation ratio. Int J Solids Struct 46(5):1105-1120. https://doi.org/10.1016/j.ijsolstr.2008. 10.015

71. Vu XH (2007) Caractérisation expérimentale du béton sous fort confinement: influences du degré de saturation et du rapport eau/ciment (Doctoral dissertation)

72. Radi E, Bigoni D, Loret B (2002) Steady crack growth in elastic-plastic fluid-saturated porous media. Int J Plast 18(3):345-358. https://doi.org/10.1016/S0749-6419(00) 00101-7
73. Gumaste KS, Rao KN, Reddy BV, Jagadish KS (2007) Strength and elasticity of brick masonry prisms and wallettes under compression. Mater Struct 40(2):241-253. https://doi.org/10.1617/s11527-006-9141-9

Publisher's Note Springer Nature remains neutral with regard to jurisdictional claims in published maps and institutional affiliations. 